\title{
Sulforaphane Attenuates Gentamicin-Induced Nephrotoxicity: Role of Mitochondrial Protection
}

\author{
Mario Negrette-Guzmán, ${ }^{1}$ Sara Huerta-Yepez, ${ }^{2}$ Omar Noel Medina-Campos, \\ Zyanya Lucía Zatarain-Barrón, ${ }^{3}$ Rogelio Hernández-Pando, ${ }^{3}$ Ismael Torres, ${ }^{4}$ \\ Edilia Tapia, ${ }^{5}$ and José Pedraza-Chaverri ${ }^{1}$ \\ ${ }^{1}$ Departamento de Biología, Facultad de Química, UNAM, 04510 Mexico City, DF, Mexico \\ ${ }^{2}$ Unidad de Investigación en Enfermedades Oncológicas, Hospital Infantil de México "Federico Gómez", \\ 06720 Mexico City, DF, Mexico \\ ${ }^{3}$ Sección de Patología Experimental, Instituto Nacional de Ciencias Médicas y Nutrición "Salvador Zubirán", \\ 14000 Mexico City, DF, Mexico \\ ${ }^{4}$ Unidad del Bioterio, Facultad de Medicina, UNAM, 04510 Mexico City, DF, Mexico \\ ${ }^{5}$ Laboratorio de Fisiopatología Renal, Departamento de Nefrología, Instituto Nacional de Cardiología \\ "Ignacio Chávez", 14080 Mexico City, DF, Mexico
}

Correspondence should be addressed to Edilia Tapia; ediliatapia@hotmail.com and José Pedraza-Chaverri; pedraza@unam.mx

Received 18 December 2012; Revised 16 February 2013; Accepted 19 February 2013

Academic Editor: José Luis Ríos

Copyright (c) 2013 Mario Negrette-Guzmán et al. This is an open access article distributed under the Creative Commons Attribution License, which permits unrestricted use, distribution, and reproduction in any medium, provided the original work is properly cited.

\begin{abstract}
Sulforaphane (SFN), an isothiocyanate naturally occurring in Cruciferae, induces cytoprotection in several tissues. Its protective effect has been associated with its ability to induce cytoprotective enzymes through an Nrf2-dependent pathway. Gentamicin (GM) is a widely used antibiotic; nephrotoxicity is the main side effect of this compound. In this study, it was investigated if SFN is able to induce protection against GM-induced nephropathy both in renal epithelial LLC-PK1 cells in culture and in rats. SFN prevented GM-induced death and loss of mitochondrial membrane potential in LLC-PK1 cells. In addition, it attenuated GMinduced renal injury (proteinuria, increases in serum creatinine, in blood urea nitrogen, and in urinary excretion on $\mathrm{N}$-acetyl- $\beta$ D-glucosaminidase, and decrease in creatinine clearance and in plasma glutathione peroxidase activity) and necrosis and apoptosis in rats. The apoptotic death was associated with enhanced active caspase-9. Caspase- 8 was unchanged in all the studied groups. In addition, SFN was able to prevent GM-induced protein nitration and decrease in the activity of antioxidant enzymes catalase and glutathione peroxidase in renal cortex. In conclusion, the protective effect of SFN against GM-induced acute kidney injury could be associated with the preservation in mitochondrial function that would prevent the intrinsic apoptosis and nitrosative stress.
\end{abstract}

\section{Introduction}

Sulforaphane (SFN) is an extraordinary potent isothiocyanate naturally occurring in Cruciferae, where it is produced by the action of the enzyme myrosinase on the glucosinolate glucoraphanin [1]. The relevance of SFN in human health has been evident with the numerous studies performed in different human populations. It has evaluated safety, metabolism, and efficacy of interventions with sprouts and extracts of broccoli as vehicle for SFN or glucoraphanin (bacterial microflora of human gastrointestinal tract owns myrosinase activity) in healthy subjects as well as other models of human sickness [2]. In recent years, SFN has attracted much attention as a natural inductor of phase II enzymes in humans and animals. It has been proposed that the induction of the nuclear translocation of Nrf2 and its binding to the antioxidant response element (ARE), whereby the cytoprotective genes transcription is activated, may occur either by disruption of NF-E2 related factor 2 (Nrf2)-Kelchlike ECH-associated protein 1 (Keap 1) interactions or by mitogen-activated protein kinases (MAPK) pathways activation $[1,3]$. Accordingly, SFN falls in the category called 
indirect antioxidants that may or may not be redox active [4], but it is known that the scavenging ability of SFN for several reactive oxygen species (ROS) is very low or negligible [5]. Interestingly, in several cytoprotective effects associated with SFN, a preservation of mitochondrial function has been found [5-12]. Guerrero-Beltrán and coworkers observed that SFN was able to prevent cisplatin-induced mitochondrial membrane potential (MMP) disruption in LLC-PK1 cells and mitochondrial permeability transition pore opening as well as other mitochondrial alterations and nephrotoxicity in rats.

On the other hand, gentamicin (GM) is a widely used worldwide aminoglycoside (AG) antibiotic in the treatment of severe infections caused by Gram-negative, mycobacteria and enterococci. This is mainly due to the typical characteristics of AGs: powerful bactericidal activity, postantibiotic effects, chemical stability, synergy with betalactam antibiotics, low cost and low levels of resistance, and because they are an effective alternative against germs insensitive to other antibiotics. However, nephrotoxicity is the principal limitation of GM therapeutic efficacy $[13,14]$. Several recent intrahospital observational studies evidence an incidence of GM-induced acute kidney injury (defined by different criteria) ranging from $20 \%$ to $35.6 \%$ [15-17]. The molecular and pathophysiological mechanisms of GM-induced nephrotoxicity are well characterized. GM is internalized through the giant endocytic complex that is preferentially expressed in the renal proximal tubular segments $S_{1}$ and $\mathrm{S}_{2}$. In these cells, GM is mainly accumulated in lysosomes, the Golgi, and endoplasmic reticulum, producing lysosomal phospholipidosis, unfolded protein response, and other effects, therefore turning on apoptotic and necrotic death pathways $[13,14]$. Nevertheless, mitochondria could be a much more sensitive target for GM. In cell culture, it has been found that GM decreases MMP, releases cytochrome c, and induces activation of caspases 9 and 3, which are elements belonging to the events cascade leading to intrinsic apoptosis [18]. In addition, induction of opening of the permeability transition pore in mitochondria isolated from kidneys of rats treated with GM was observed [19].

Because of the emergent importance of mitochondria in the renal toxicity induced by GM, it has been claimed that all of strategies that tend to preserve the normal kidneys performance in patients under an AG treatment scheme will require protection of renal mitochondria [20]. Considering all of the SFN qualities and knowing the nephrotoxicity mechanism of GM, we hypothesized that SFN is able to prevent GM-induced nephrotoxicity. The aim of the present study was to evaluate whether SFN induces a cytoprotective effect on a model of GM-induced acute kidney injury and cultured cells LLC-PK1 treated with GM.

\section{Materials and Methods}

2.1. Chemicals and Reagents. SFN (Cat. no. S8044, batch 26817812) was obtained from LKT Laboratories (St. Paul, MN, USA). GM (Garamicina G.U. $160 \mathrm{mg} / 2 \mathrm{~mL}$, batches 0DPDA006 and 1DPDA002) was purchased from ScheringPlough (México, DF). Dulbecco's Modified Eagle Medium
(DMEM), fetal bovine serum (FBS), trypsin, antibiotic $(10,000 \mathrm{U} / \mathrm{mL}$ penicillin and $10,000 \mu \mathrm{g} / \mathrm{mL}$ streptomycin), $0.4 \%$ trypan blue solution, and other tissue culture reagents were purchased from Gibco (México, DF). Cell culture plates were from Nunc (Roskilde, Denmark). 3-(4,5-dimethylthiazol-2-yl)-2,5-diphenyltetrazolium bromide (MTT), dimethylsulfoxide (DMSO), paraformaldehyde, triton X-100, bovine serum albumin (BSA), $p$-nitrophenyl- $N$-acetyl- $\beta$,Dglucosaminide, nicotinamide adenine dinucleotide reduced form (NADPH), glutathione reductase (GR), and glutathione (GSH) were purchased from Sigma-Aldrich (St. Louis, MO, USA). Trichloroacetic acid (TCA) and hydrogen peroxide $\left(\mathrm{H}_{2} \mathrm{O}_{2}\right)$ were obtained from J. T. Baker (Xalostoc, Edo. de México, México). Vybrant Apoptosis Assay Kit \# 3, containing annexin $\mathrm{V}$ conjugated to fluorescein (annexin V-FITC) and propidium iodide (PI), and 5,5',6,6' -tetrachloro-1,1',3,3' tetraethylbenzimidazolyl-carbocyanine iodide (JC-1) were obtained from Molecular Probes, Inc. (Eugene, OR, USA). Mouse monoclonal anti-nitrotyrosine (3-NT) antibody (Cat. no. 189542) was purchased from Cayman Chemical (Ann Arbor, MI, USA). Mouse IgG2a $\kappa$ isotype control (Cat. no. 550339) was purchased from BD Biosciences (San Jose, CA, USA). Rabbit polyclonal anti-caspase 8 antibody (Cat. no. ab4052) was purchased from Abcam Inc. (Cambridge, MA, USA). Goat polyclonal anti-cleaved caspase 9 p10 (h331) antibody (Cat. no. sc-22182), donkey anti-mouse IgG-B biotin-conjugated secondary antibody (Cat. no. sc2098), rabbit anti-goat IgG-B biotin-conjugated secondary antibody (Cat. no. sc-2774), goat anti-rabbit IgG-B biotinconjugated secondary antibody (Cat. no. sc-2040), normal goat IgG (Cat. no. sc-2028), and normal rabbit IgG (Cat. no. sc-2027) were obtained from Santa Cruz Biotechnology Inc. (Santa Cruz, CA, USA). In Situ Cell Death Detection Kit, POD (Cat. No. 11684817 910), was obtained from Roche Applied Science (Mannheim, Germany). Streptavidinhorseradish peroxidase (HRP) and 3,3'-diaminobenzidine (DAB) were obtained from Dako (Carpintería, CA, USA). All other used reagents and compounds were reactive grade and commercially available.

2.2. Cell Culture and Viability. Lily Laboratory Culture Porcine Kidney (LLC-PK1, porcine renal epithelium) cells were obtained from American Type Culture Collection (Rockville, MD, USA). This cell line is an accepted model to study AG toxicity [21-23]. LLC-PK1 cells were maintained in DMEM supplemented with $10 \%$ FBS and $1 \%$ of antibiotic and cultured under permissive conditions: $37^{\circ} \mathrm{C}$ and $5 \% \mathrm{CO}_{2}$ [8]. In order to evaluate the effect of SFN on GM-induced toxicity, cells were seeded at a density of $4 \times 10^{4}$ cells $/ \mathrm{cm}^{2}$ onto 48 well plates and used for the experiment on the following day. Cells were incubated for $24 \mathrm{~h}$ with SFN $(1-10 \mu \mathrm{M})$ or medium before the GM addition. At the end of preincubation period SFN or culture medium was replaced by fresh SFN or medium, adding $8 \mathrm{mM}$ GM to some cells groups in order to induce toxicity. Every $24 \mathrm{~h}$, along $72 \mathrm{~h}$ of GM exposure, the culture medium was replaced by fresh medium with the same previous characteristics [24]. Cell viability was assessed by MTT reduction [8]. At the end of $96 \mathrm{~h}$ of experiment, medium was removed and cells were washed twice with 
phosphate-buffered saline (PBS) pH 7.4. Thereafter, cells were incubated in medium containing MTT $(0.125 \mathrm{mg} / \mathrm{mL})$ at $37^{\circ} \mathrm{C}$ for $1 \mathrm{~h}$ in humidified air supplemented with $5 \%$ $\mathrm{CO}_{2}$. Medium was then discarded, and the formazan crystals deposited in each well bottom were dissolved in $200 \mu \mathrm{L}$ of $0.1 \mathrm{~N} \mathrm{HCl}$ in isopropanol. Absorbance was determined at $570 \mathrm{~nm}$ using a Synergy HT multimode microplate reader (Biotek Instruments Inc., Winooski, VT, USA). In additional experiments, bright field images were obtained by phase contrast microscopy (Nikon Eclipse TS100F, Nikon Co., Tokyo, Japan) to compare cell morphology in all experimental conditions.

2.3. Cell Death Assays. In order to estimate cell death and characterize its phenotypes, LLC-PK1 detached cells in 24well plates (CT, $5 \mu \mathrm{M}$ SFN, $8 \mathrm{mM}$ GM and SFN + GM groups) were collected from media, pelleted by centrifugation $(1000 \times \mathrm{g}, 3 \mathrm{~min})$ and counted in a haemocytometer at 24 , 48 , and $72 \mathrm{~h}$ of GM exposure. Attached cells were also counted at the end of the GM treatment by trypsinization and using the trypan blue exclusion assay. Viable cells were sorted by this technique. Because there was a lot of cell fragmentation (mainly in the GM and SFN + GM groups), only attached cells were incubated in annexin V-FITC and PI probes at the end of the GM treatment $[25,26]$. After 15 min of incubation with annexin V-FITC/PI solution, cells were washed with annexin $\mathrm{V}$-binding buffer (10 mM HEPES, $140 \mathrm{mM} \mathrm{NaCl}, 2.5 \mathrm{mM} \mathrm{CaCl}_{2}, \mathrm{pH} \mathrm{7.4)}$ and photographed in a Nikon Eclipse TS100F inverted microscope provided with G-2A (excitation 510-560 $\mathrm{nm}$ and emission $590 \mathrm{~nm}$ ) and B-2A (excitation $450-490 \mathrm{~nm}$ and emission $515 \mathrm{~nm}$ ) filters. Thereafter cells were trypsinized, centrifuged, resuspended in $100 \mu \mathrm{L}$ of annexin V-binding buffer, and put in a black microplate and their fluorescence emission was measured at 528 (annexin V-FITC) and 600 (PI) nm in a Synergy HT multimode microplate reader.

2.4. MMP Measurements. MMP was assessed by using the cationic lipophilic fluorescence dye JC-1 which forms potential-dependent J-aggregates [27]. The cells were first seeded in 24-well plates and used for the experiment on the following day. Thereafter, cells were incubated for $24 \mathrm{~h}$ with $5 \mu \mathrm{M}$ SFN or medium and then were treated with GM $(8 \mathrm{mM}), \mathrm{SFN}+\mathrm{GM}, \mathrm{SFN}$, or medium. Following the exposure to GM for $1,3,6,12$ and $24 \mathrm{~h}$, the medium was replaced by medium containing $10 \mu \mathrm{M}$ JC-1 and cells were incubated at $37^{\circ} \mathrm{C}$ for $30 \mathrm{~min}$ in the dark. Cells were then rinsed with PBS and examined under an inverted microscope (Nikon, Eclipse TS 100) provided with G-2A filter (excitation 510-560 $\mathrm{nm}$ and emission $590 \mathrm{~nm}$ ) for qualitative studies $[8,18]$.

2.5. Animals. Male Wistar rats with an initial body weight of $230-260 \mathrm{~g}$ were used. Animals were maintained under $12 \mathrm{~h}$ light/dark cycles at controlled temperature, having ad libitum access to water and standard food. This experimental study was approved by the Local Committee for the Care and Use of Laboratory Animals (FQ/CICUAL/038/12) and was conducted according to the guidelines of Mexican Official
Norm Guide for the use and care of laboratory animals (NOM-062-ZOO-1999) and for the disposal of biological residues (NOM-087-ECOL-1995).

2.6. Experimental Design. Animals were randomly divided into four groups: (i) control group (CT, $n=8$ ): the animals were injected subcutaneously (s.c.) with isotonic saline solution (ISS) every $12 \mathrm{~h}$ for 4 days, an additional daily injection with ISS (vehicle of SFN) was made intraperitoneally (i.p.) at a time between the previously described injections; (ii) the rats of SFN group $(n=8)$ were administered s.c. with ISS and i.p. with SFN (1.0 mg/kg/24h) dissolved in ISS; (iii) the rats of the GM group $(n=12)$ were administered s.c. with GM at a dose of $70 \mathrm{mg} / \mathrm{kg} / 12 \mathrm{~h}$ instead of ISS every $12 \mathrm{~h}$ $[28,29]$, ISS was injected once every day during the 4 days of treatment; and (iv) rats of the SFN + GM group $(n=10)$ were injected s.c. with $70 \mathrm{mg} / \mathrm{kg}$ of GM every $12 \mathrm{~h}$ during 4 days and i.p. with SFN $1.0 \mathrm{mg} / \mathrm{kg} / 24 \mathrm{~h}$ between the two daily GM injections. On the fourth day of treatment, rats were placed in metabolic cages to collect $24 \mathrm{~h}$ urine for the measurement of nephrotoxicity markers (proteinuria and urinary excretion of $\mathrm{N}$-acetyl- $\beta$-D-glucosaminidase (NAG)). At the end of this period rats were anesthetized with an injection of sodium pentobarbital $(60 \mathrm{mg} / \mathrm{kg})$ and blood was obtained via aorta using a syringe containing heparin and a needle no.18 at room temperature. Plasma was separated and stored at $-20^{\circ} \mathrm{C}$ until further markers of renal damage (plasma creatinine, creatinine clearance, blood urea nitrogen (BUN), and activity of glutathione peroxidase $(\mathrm{GPx})$ in plasma) were measured. Right kidney was quickly removed, weighed, divided in $\approx 0.3 \mathrm{~g}$ slices and frozen on liquid nitrogen, and stored at $-80^{\circ} \mathrm{C}$. Remaining kidney was perfused with PBS pH 7.4 and $4 \%$ formaldehyde solution in PBS, removed, and preserved in formaldehyde solution for histopathological and immunohistochemistry studies.

2.7. Analytical Methods. BUN and creatinine in plasma and urine were measured using an autoanalyzer. Creatinine clearance was calculated with the standard formula. Proteinuria was determined by a turbidimetric method using $12.5 \%$ TCA and $420 \mathrm{~nm}$ as wavelength [30, 31]. Urinary NAG activity was determined measuring the anionic form of $p$-nitrophenol at $405 \mathrm{~nm}$ at alkaline $\mathrm{pH}$; this molecule is formed from $p$ nitrophenyl- $N$-acetyl- $\beta$-D-glucosaminide which is used in the assay as NAG substrate [32].

2.8. Histopathological Studies. The kidney fixed in formaldehyde was dehydrated in graded ethylic alcohol and embedded in paraffin. Sections of $3 \mu \mathrm{m}$ thickness were obtained for staining with hematoxylin-eosin $(\mathrm{H} \& \mathrm{E})$ and the quantitative histological damage was determined by a Leica QWin Image Analyzer (Cambridge, UK) [30].

2.9. Immunohistochemistry and Digital Pathology Analysis. Immunohistochemical staining for caspase-8, cleaved caspase-9, and 3 -NT was performed in $3 \mu \mathrm{m}$ deparaffinized renal tissue slices. Antigens were recuperated by boiling for $20 \mathrm{~min}$ in $0.01 \%$ sodium citrate solution, $\mathrm{pH}$ 6.0. Endogenous 
peroxidase activity was blocked with $3 \% \mathrm{H}_{2} \mathrm{O}_{2}$ solution in methanol for 30 minutes. Antibody nonspecific binding was inhibited by incubation in a $2 \%$ solution of normal swine serum in PBS (PBS-NSS) for $60 \mathrm{~min}$. Slides were incubated overnight at room temperature with anti-caspase8 (1:500) anti-cleaved caspase-9 $(1: 1,000)$, and anti-3-NT $(1: 250)$ primary antibodies. The following day, slides were washed five times for $8 \mathrm{~min}$ in PBS $1 \mathrm{x} \mathrm{pH}$ 7.4. After washing, slides were incubated for $30 \mathrm{~min}$ at room temperature with a second biotinylated antibody $(1: 500)$ and for $30 \mathrm{~min}$ at room temperature with streptavidin conjugated to HRP. For color developing, $\mathrm{DAB}$ was used from one to five min. The reaction was stopped with distilled water and the slides were counterstained with hematoxylin. Finally, tissues were dehydrated and fixed with Mount E-2 medium (Shandon Laboratory, Pittsburgh, PA, USA). Slides were scanned in order to obtain electronic files. Immunohistochemical stains were digitally analyzed with Aperio CS (San Diego, CA, USA) digital pathology equipment, and expression density (brown color) in five $10^{6} \mu \mathrm{m}^{2}$ areas belonging to the renal cortex was evaluated with an algorithm determining pixel density with the program included in the Aperio ScanScope System (San Diego, CA, USA). Active caspase-9 sections were analyzed under a microscope Olympus BX-40 and immunopositives regions were quantified using the software Image-Pro Plus 6.2, Media Cybernetics (Silver Spring, MD, USA). Based on the obtained results, the mean was calculated for each rat and for each group. In order to decrease variability, all the samples in each group were simultaneously processed in one experiment and a single antibody aliquot diluted in PBS-NSS was used.

2.10. Apoptosis Detection. DNA fragmentation was evaluated by terminal-deoxynucleotidyltransferase mediated dUTPdigoxigenin nick end labeling (TUNEL) in renal tissue samples. $3 \mu \mathrm{m}$ sections were subjected to the same immunohistochemical procedure described previously until blocking with PBS-NSS. The enzyme terminal transferase (Tdt) was subsequently added in a 1:50 mixture in buffer solution (including fluorescein-conjugated oligonucleotides) to the tissues and incubated for $50 \mathrm{~min}$ at $37^{\circ} \mathrm{C}$ in the dark. Tissues were washed 5 times for $5 \mathrm{~min}$ in PBS $1 \mathrm{x}$ and subsequently incubated for $30 \mathrm{~min}$ with the anti-fluorescein antibody at $37^{\circ} \mathrm{C}$. After washing, color was developed by adding DAB and monitored under the light microscope. Slides were scanned and TUNEL-positive nuclei were analyzed with digitalized pathology equipment as described before in the immunohistochemical studies.

2.11. Antioxidant Enzymes. Catalase (CAT) activity was assayed in renal cortex by a method based on the disappearance of $\mathrm{H}_{2} \mathrm{O}_{2}$ at $240 \mathrm{~nm}$ and glutathione peroxidase (GPx) activity was measured, in blood plasma and renal cortex, by the disappearance of NADPH at $340 \mathrm{~nm}$ in a reaction coupled with the enzyme GR [33].

2.12. Statistics. Results are expressed as mean \pm SEM. Data were analyzed by one-way ANOVA followed by Bonferroni's multiple comparisons test using the software Prism 5.00,
GraphPad (San Diego, CA, USA). A $P$ value less than 0.05 was considered statistically significant.

\section{Results}

3.1. SFN Induces an Increase in MTT Reduction and Prevents the GM-Induced Death in LLC-PK1 Cells. Figure 1 shows representative phase contrast micrographs and quantification of cell viability by MTT reduction of LLC-PK1 cells under different experimental conditions. Interestingly, an increase in MTT reduction was observed in cells incubated only with 1-7.5 $\mu \mathrm{M}$ SFN. At $5.0 \mu \mathrm{M}$ SFN, the MTT reduction average was $42.8 \%$ greater than that of untreated cells (Figure $1(\mathrm{e})$ ). The $72 \mathrm{~h}$ incubation with GM decreased the number of cells (Figure 1(c)) and cell viability (expressed as MTT reduction) to $60.4 \%$ (Figure 1(f)). A protective effect by SFN was also found at $1,3,5$, and $7.5 \mu \mathrm{M}$. Even though a clear lineal correlation between viability and SFN concentration was not observed, the protection of SFN was evident with viabilities ranging from $83.9 \%$ to $92.8 \%$ of the control value (cells without treatment). The maximum increase in MTT reduction of cells coincubated with SFN and GM was observed at $5.0 \mu \mathrm{M}$ SFN (Figures 1(d) and 1(f)).

Table 1 exhibits the number of detached cells for each day of treatment as well as the counting of trypan bluestained and viable cells from the attached cell fraction. This allows estimating the cell death level in the entire treatment. It should be taken into account that there is an underestimation of death events due to cell fragmentation, which was extensive in GM and SFN + GM groups. However, in this way, more death events could be counted 2.4 times in cells treated with GM than in control cells. It was also observed that the events of death in cells treated with $5 \mu \mathrm{M}$ SFN and $8 \mathrm{mM}$ GM were approximately $67 \%$ of those of GM cells. Viability could be also determined by this means. It is observed that viable cells in the GM group fall until $25 \%$ of the control cells while in SFN + GM cells this fall is avoided showing a value of 57\% related to CT group (Figure 2). Interestingly, these outcomes were different from those obtained through the MMT reduction method even though the trend in the protective effect is conserved (Figures 1(e) and 1(f)).

3.2. SFN Prevents GM-Induced Apoptosis in LLC-PK1 Cells. Necrosis and apoptosis in LLC-PK1 cells treated with SFN and GM were also estimated using the Vibrant Apoptosis Assay Kit \# 3. Figure 3(a) shows signals due to annexin VFITC and PI, indicating apoptosis and necrosis, respectively. Apparently, fluorescence intensities and areas are similar in all cell groups however, the difference in cell density for the bright field images of each group should be noticed. In Figure 3(b), it is plotted the fluorescence intensity corrected by the number of cells in each group. Relying on these data, it can be inferred that there was an increase of 1.5 -fold in the necrosis and 4.8-fold in apoptosis in cells incubated with GM compared to CT cells. The increase in apoptosis death was significantly attenuated by the treatment with SFN.

3.3. SFN Preserves MMP in LLC-PK1 Cells Treated with GM. Mitochondrial depolarization was observed in LLC-PK1 cells 


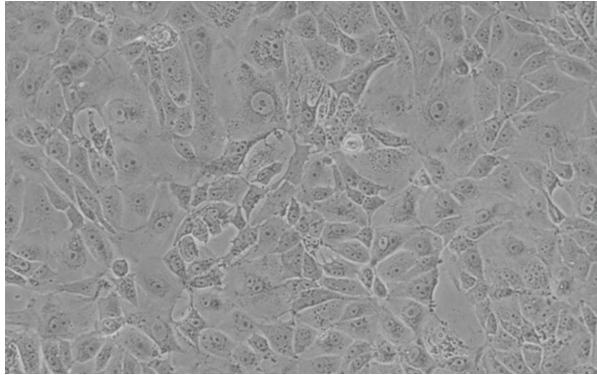

(a)

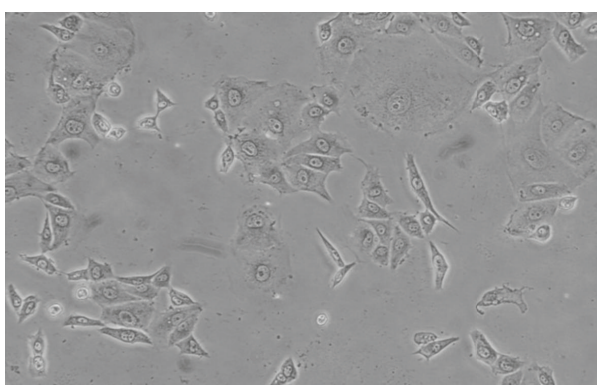

(c)

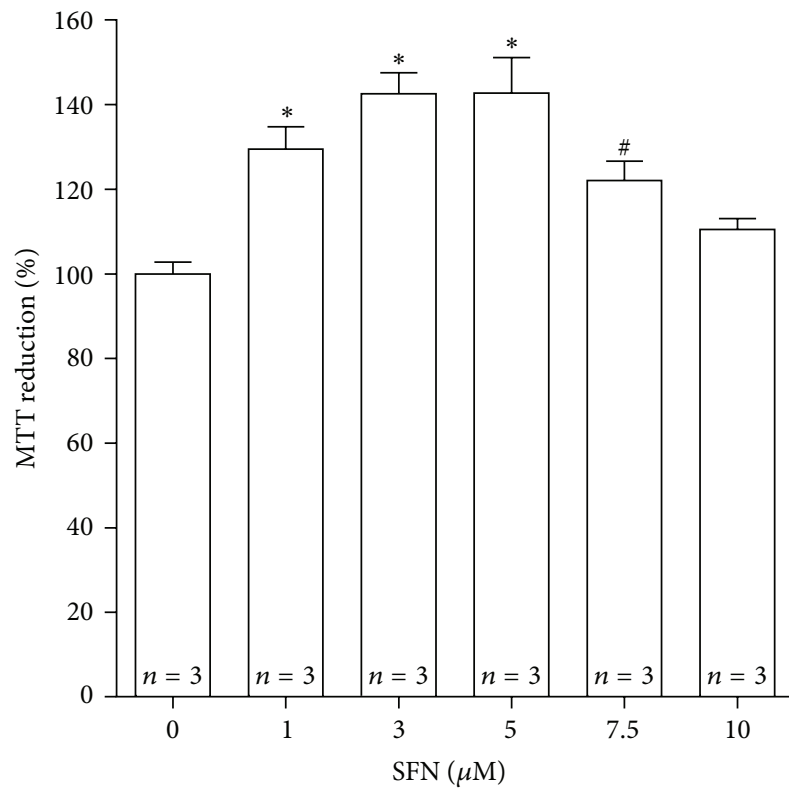

(e)

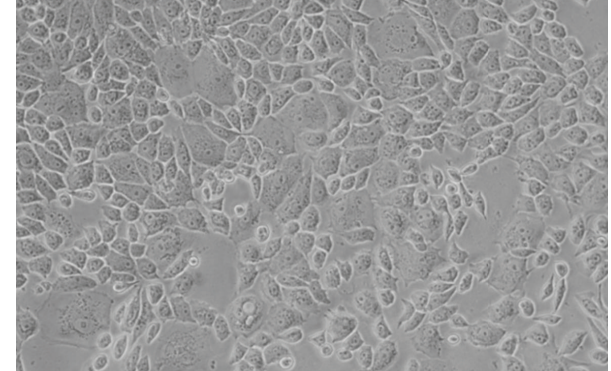

(b)

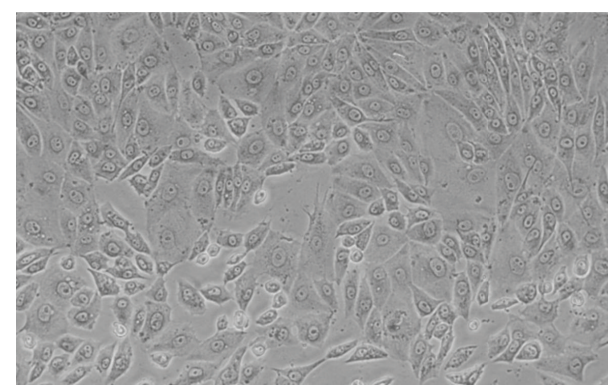

(d)

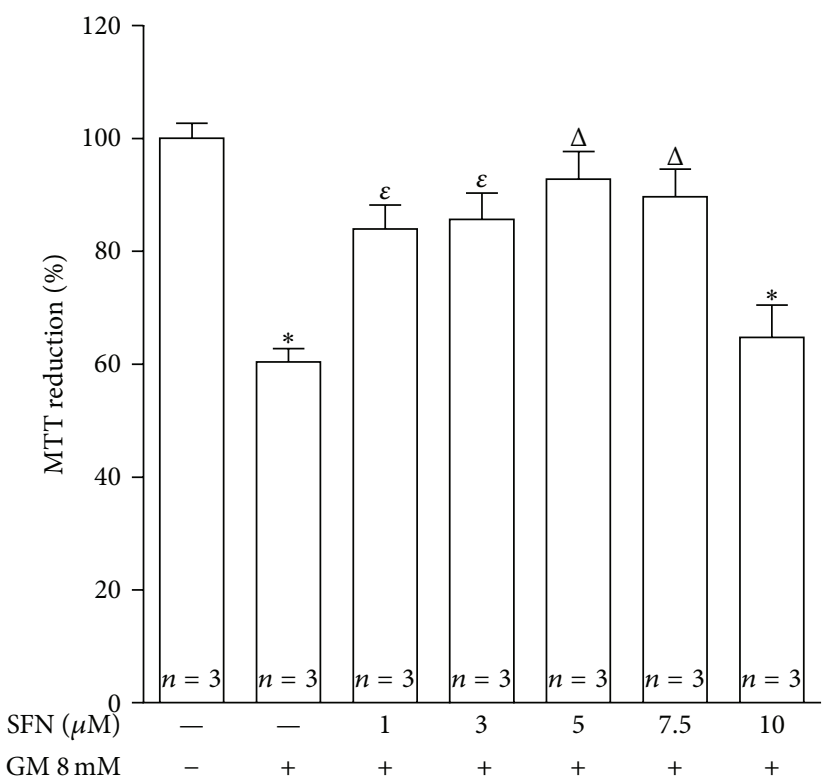

(f)

FIGURE 1: SFN prevents GM-induced death in LLC-PK1 cells. (a-d) Representative images (10x) of LLC-PK1 cells obtained by phase contrast microscopy and (e, f) cell viability (MTT reduction) in the groups under study. A decrease in the number of cells exposed to (c) $8 \mathrm{mM}$ GM for $72 \mathrm{~h}$ related to (a) cells without treatment can be observed. This decrease was prevented in (d) cells pretreated with $5 \mu \mathrm{M}$ SFN for $24 \mathrm{~h}$ and coincubated with $5 \mu \mathrm{M}$ SFN and $8 \mathrm{mM}$ GM for $72 \mathrm{~h}$. (e) Effect of SFN on viability of LLC-PK1 cells. Cells were incubated with 1-10 $\mu \mathrm{M}$ SFN for $96 \mathrm{~h}$. (f) SFN prevents GM-induced cell death. Cells were incubated with 1-10 $\mu \mathrm{M}$ SFN for $24 \mathrm{~h}$ and then they were coincubated with 1-10 $\mu \mathrm{M}$ SFN and $8 \mathrm{mM}$ GM for $72 \mathrm{~h}$. Control cells were incubated (e) without SFN or (f) without SFN and GM. Data are mean \pm SEM. ${ }^{*} P<0.001$, ${ }^{\#} P<0.05$ versus control cells; ${ }^{\varepsilon} P<0.01,{ }^{\Delta} P<0.001$ versus GM-treated cells.

after $3 \mathrm{~h}$ of GM incubation (green color in the picture, Figure 4). In cells pretreated and coincubated with SFN, the loss of MMP induced by GM was prevented (orange staining in the picture, Figure 4). This trend remained until $6 \mathrm{~h}$. In remarkable way, remaining cells after $12 \mathrm{~h}$ of GM exposure (without SFN) seem to recover their MMP but the decrease in the cell number began to be evident.

3.4. SFN Treatment Attenuates GM-Induced Renal Dysfunction and Damage in Rats. Neither urinary volume nor body 
TABLE 1: Counting of daily detached, trypan blue stained and viable LLC-PK1 cells during the GM exposure and SFN treatment.

\begin{tabular}{lcccc}
\hline & CT & SFN & GM & SFN + GM \\
\hline DC/well 24h & $1,483 \pm 367$ & $483 \pm 60$ & $5,487 \pm 247^{*}$ & $1,113 \pm 567^{\#}$ \\
DC/well 48 h & $1,633 \pm 109$ & $1,117 \pm 469$ & $8,033 \pm 324^{*}$ & $4,250 \pm 375^{\#}$ \\
DC/well 72 h & $2,867 \pm 192$ & $2,883 \pm 259$ & $8,017 \pm 760^{\varepsilon}$ & $4,733 \pm 838^{\Delta}$ \\
TBS cells/well (attached after GM exposure) & $16,517 \pm 3,219$ & $23,733 \pm 8,020$ & $31,800 \pm 3,318$ & $25,433 \pm 829$ \\
Total death cells/well & $22,500 \pm 3,399$ & $28217 \pm 8,366$ & $53,337 \pm 3,714^{\varepsilon}$ & $35,550 \pm 1,422$ \\
Viable cells/well & $106,450 \pm 4,976$ & $94,317 \pm 5,874$ & $26,883 \pm 4,681^{*}$ & $60,400 \pm 5,765^{\Delta}$ \\
\hline
\end{tabular}

CT: cells without treatment. SFN: cells incubated in $5 \mu \mathrm{M}$ SFN. GM: cells in $8 \mathrm{mM} \mathrm{GM}$. SFN + GM: cells coincubated in $5 \mu \mathrm{M}$ SFN and $8 \mathrm{mM}$ GM. DC: detached cells. TBS: trypan blue stained. Total death cells $=$ DC $24 \mathrm{~h}+$ DC $48 \mathrm{~h}+$ DC $72 \mathrm{~h}+$ TBS cells. Cells attached after GM exposure include TBS cells + viable cells. Data are mean $\pm \mathrm{SEM}, n=3 .{ }^{*} P<0.001$ versus $\mathrm{CT} ;{ }^{\#} P<0.001$ versus $\mathrm{GM} ;{ }^{\varepsilon} P<0.01$ versus $\mathrm{CT} ;{ }^{\Delta} P<0.05$ versus GM.

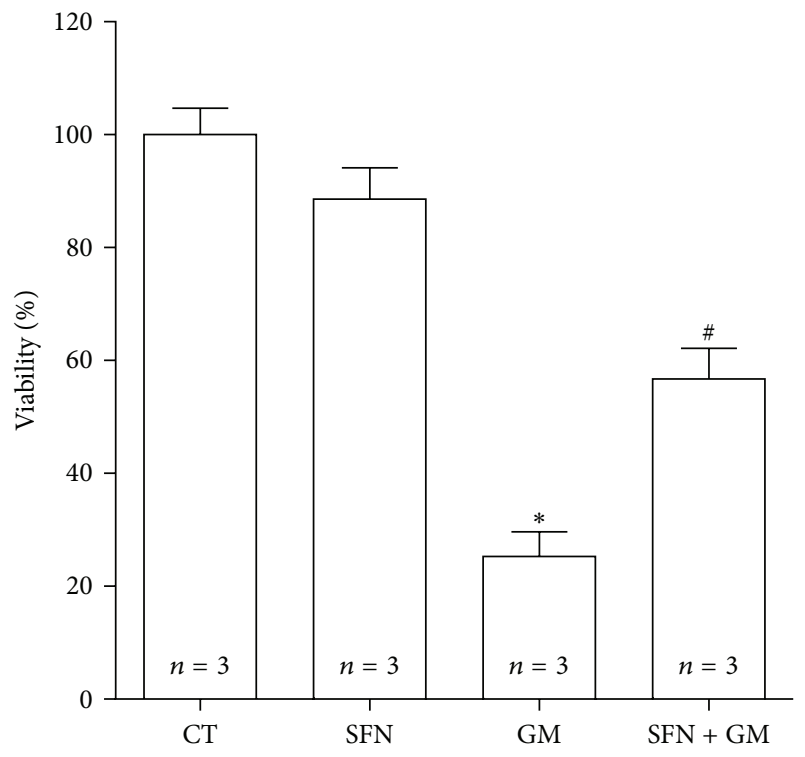

FIGURE 2: SFN attenuates GM-induced viability drop in LLC-PK1 cells. Cells were incubated with $5 \mu \mathrm{M}$ SFN for $24 \mathrm{~h}$ (SFN and SFN + GM) and then they were co-incubated with $5 \mu \mathrm{M}$ SFN (SFN and $\mathrm{SFN}+\mathrm{GM})$ and $8 \mathrm{mM}$ GM for $72 \mathrm{~h}(\mathrm{GM}$ and SFN + GM). Control cells (CT) were incubated without SFN and GM. Viability was determined by the trypan blue exclusion assay. Data are mean \pm SEM. ${ }^{*} P<0.001$ versus $C T$; ${ }^{\#} P<0.05$ versus $\mathrm{GM}$.

weight was affected by treatment with SFN or GM (Table 2). In contrast, renal weight and right kidney ratio [(kidney weight/body weight $) \times 100$ ] show an increase in the GM group compared to the CT group $(P<0.001)$, which could not be ameliorated by the SFN treatment (Table 2).

Figures 5 and 6 show the protective effect of SFN against GM-induced renal injury in rats. GM induced an increase in plasma creatinine levels (Figure 5(a)). The GM group showed increased levels of plasma creatinine $(1.35 \pm 0.06 \mathrm{mg} / \mathrm{dL})$ versus CT group $(0.61 \pm 0.04 \mathrm{mg} / \mathrm{dL})$. Plasma creatinine decreased in the SFN + GM group $(0.91 \pm 0.05 \mathrm{mg} / \mathrm{dL}$, $P<0.01$ versus GM). Similar trends were observed in creatinine clearance (Figure 5(b)), BUN (Figure 5(c)), and plasma GPx (Figure 5(d)). There was a decrease of just over $50 \%$ in creatinine clearance in the GM group compared to rats treated only with vehicle. SFN treatment allowed a recuperation of almost $75 \%$ of clearance capacity in the SFN + GM group compared to CT group (CT: $0.75 \pm 0.02 \mathrm{~mL} / \mathrm{min}$; GM: $0.34 \pm 0.03 \mathrm{~mL} / \mathrm{min} ; \mathrm{SFN}+\mathrm{GM}: 0.56 \pm 0.04 \mathrm{~mL} / \mathrm{min})$. BUN increased in the GM group $(52.5 \pm 2.6 \mathrm{mg} / \mathrm{dL})$ compared to the CT group $(25.9 \pm 1.8 \mathrm{mg} / \mathrm{dL}, P<0.001)$ and this increase was attenuated in the SFN + GM group $(40.2 \pm 3.2 \mathrm{mg} / \mathrm{dL}$, $P<0.01$ versus GM). GPx activity showed a decrease of $1 \mathrm{U} / \mathrm{mL}$ in the GM group compared to CT group (GM: $1.26 \pm$ $0.09 \mathrm{U} / \mathrm{mL}$ versus CT: $2.26 \pm 0.11 \mathrm{U} / \mathrm{mL}$ ). However, a partial reestablishment of the activity to $1.68 \pm 0.07 \mathrm{U} / \mathrm{mL}$ in the SFN + GM group compared to the GM group was noted. GPx activity was similar in the CT and SFN groups. The increase of both urinary excretion of total protein (39.1 \pm $2.7 \mathrm{mg}$ of protein $/ 24 \mathrm{~h}$ ) and the lysosomal enzyme NAG (10.9 $\pm 0.9 \mu \mathrm{mol} / \mathrm{min} / 24 \mathrm{~h}$ ) accounted for the important tubular injury induced by GM (Figures 6(a) and 6(b)). The treatment with SFN induced a remarkable attenuation of proteinuria and NAG excretion in the SFN + GM group to $23.1 \pm 2.4 \mathrm{mg}$ of protein $/ 24 \mathrm{~h}$ and $4.8 \pm 0.9 \mu \mathrm{mol} / \mathrm{min} / 24 \mathrm{~h}$, respectively $(P<$ $0.001)$.

3.5. SFN Diminishes GM-Induced Histological Alterations in Rat Renal Cortex. GM induced specific damage in the cortical convoluted tubules. This damage was variable, from mild cellular edema with loss of the apical brush border to extensive necrosis with cells detachment and luminal casts constituted by cellular debris (Figure 7). The percentage of affected tubules determined by automated morphometry in this group was of $88 \%$, while the mean of damaged area in the convoluted proximal tubules was of $71 \%$. SFN treatment induced a significant protection, as demonstrated by automated morphometry, which showed $31 \%$ of affected cortical tubules with $17 \%$ of damaged tubular area (Figures $7(\mathrm{e})$ and $7(\mathrm{f})$ ). Kidney sections from control animals treated only with SFN or saline solution did not show any histological abnormality (Figures 7(a) and 7(b)).

3.6. SFN Attenuates GM-Induced Intrinsic Apoptosis in Renal Tubules and Glomeruli. Conventional histology showed numerous tubular epithelial cells with hyperchromatic condensed nuclei and conserved cytoplasm suggesting apoptosis. In order to be more specific, apoptotic cells were revealed in 


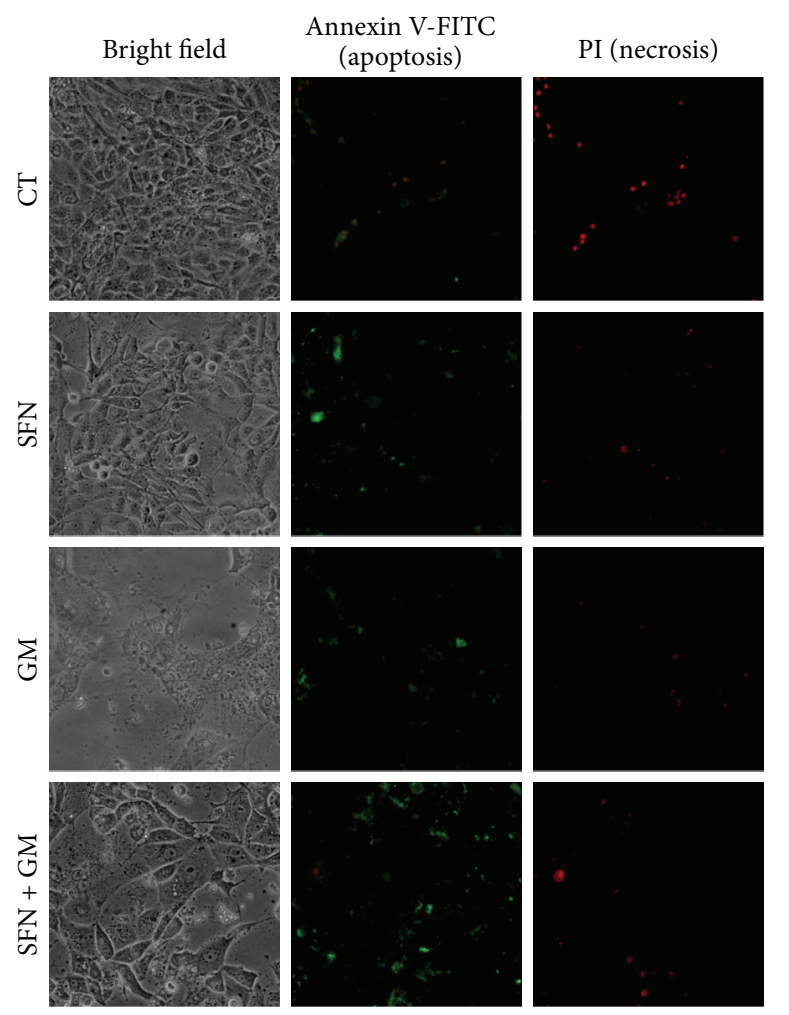

(a)

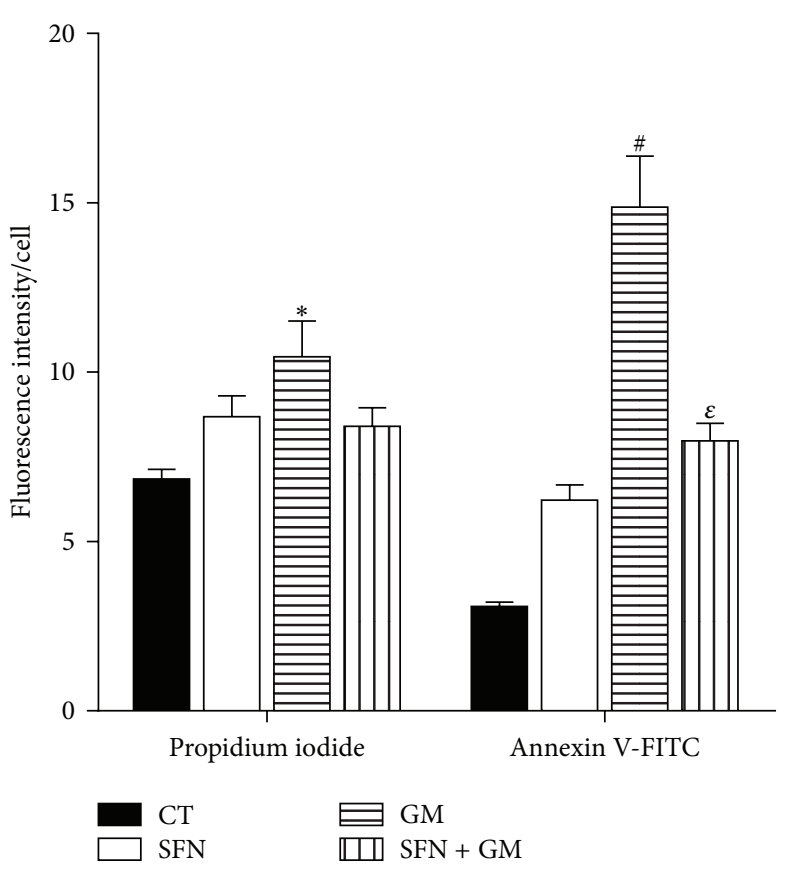

(b)

FIGURE 3: SFN prevents GM-induced apoptosis in LLC-PK1 cells. (a) Representative images (20x) obtained by fluorescence microscopy showing necrotic and apoptotic LLC-PK1 cells after $72 \mathrm{~h}$ of exposure to GM. Necrotic cells were stained with PI and apoptotic cells were stained with the annexin V-FITC probe. Cells were incubated with (SFN and SFN + GM groups) or without (CT and GM groups) $5 \mu \mathrm{M}$ SFN for $24 \mathrm{~h}$, followed by the addition of $8 \mathrm{mM} \mathrm{GM}(\mathrm{GM}), 5 \mu \mathrm{M}$ SFN (SFN), $5 \mu \mathrm{M}$ SFN $+8 \mathrm{mM}$ GM (SFN + GM), or medium (CT) for $72 \mathrm{~h}$. All of groups showed similar PI and annexin V-FITC fluorescence, but the cell population was different between them (bright field photographs). (b) Fluorescence intensity corrected for cell number (measured by trypan blue exclusion assay, TBS cells/well + viable cells/well in Table 1) of each group. After pictures taking, fluorescence intensity was measured as was explained in Section 2.3.Data are mean \pm SEM of 3 independent experiments. ${ }^{*} P<0.05,{ }^{\#} P<0.001$ versus $\mathrm{CT} ;{ }^{\varepsilon} P<0.01$ versus GM.

TABLE 2: Urine volume, body weight, right kidney weight, and right kidney ratio at the end of treatment in all the studied groups.

\begin{tabular}{lcccc}
\hline & CT & SFN & GM & SFN + GM \\
\hline Urine volume (mL/day/100 g BW) & $5.9 \pm 0.5$ & $5.7 \pm 1.4$ & $8.4 \pm 0.9$ & $6.7 \pm 1.1$ \\
Body weight (g) & $238.9 \pm 5.1$ & $227.0 \pm 4.4$ & $226.0 \pm 4.0$ & $222.2 \pm 3.4$ \\
Right kidney weight (g) & $0.89 \pm 0.02$ & $0.91 \pm 0.03$ & $1.13 \pm 0.04^{*}$ & $1.12 \pm 0.03^{*}$ \\
Right kidney ratio (\%) & $0.37 \pm 0.01$ & $0.40 \pm 0.01$ & $0.50 \pm 0.01^{*}$ & $0.50 \pm 0.01^{*}$ \\
\hline
\end{tabular}

BW: body weight. Kidney ratio $=($ kidney weight/body weight $) \times 100$. Data are mean $\pm \mathrm{SEM}, n=8-12 .{ }^{*} P<0.001$ versus CT.

situ by TUNEL technique and quantified by automated morphometry (Figure 8). TUNEL-positive tubular and glomerular cells in kidneys of rats treated with GM are shown in Figure 8(c). Strongly stained nuclei were observed depicting early apoptosis as well as a weaker cytoplasmic staining mainly in tubules (Figure 8(c)). TUNEL positive cells were clearly decreased in the SFN + GM group (Figure 8(d)). Quantitative data, expressed as percentage of TUNELpositive nuclei, revealed that TUNEL positivity was 7-fold higher in the GM group than in the CT group $(P<0.001)$, while the positive nuclei in the SFN + GM group were $40 \%$ of those found in the GM group $(P<0.001$, Figure $8(\mathrm{e}))$.
In order to investigate whether apoptosis was mediated by caspases as well as the apoptosis pathway involved, caspase8 and caspase- 9 were determined by immunohistochemistry. Caspase- 8 was unchanged in all the studied groups (data not shown). Immunostaining of the active form of caspase- 9 was observed predominately in the cytoplasm of damaged tubular cells, particularly in detached cells located in the tubular lumen and in few mesangial glomerular cells of the GM group (Figure 9(d)), being evidently higher when compared to the CT group (Figure 9(b)). The integrated optical density (IOD) was 4.6-fold higher in the GM group compared to that found in the CT group $(P<0.05$, Figure $9(\mathrm{f}))$, while IOD measuring 
CT
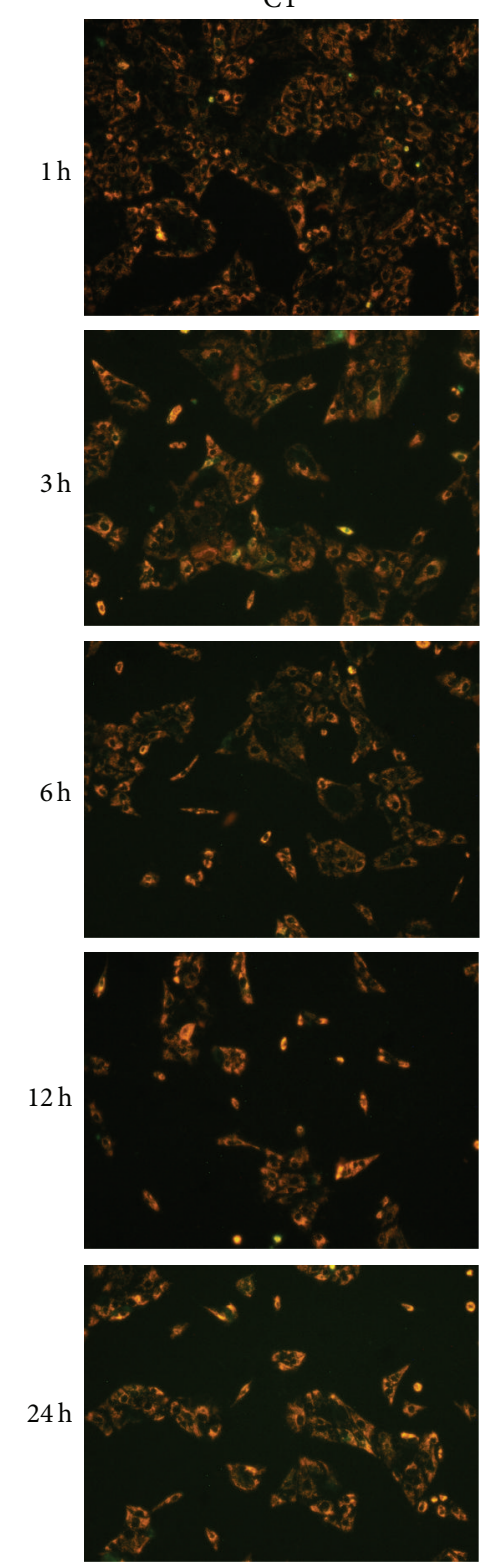

SFN
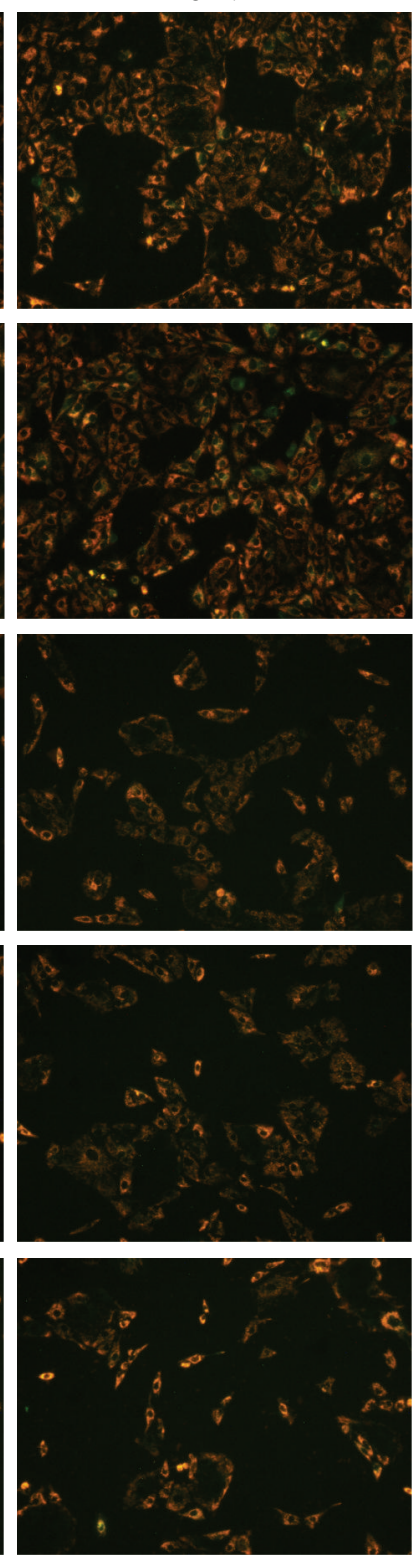

GM
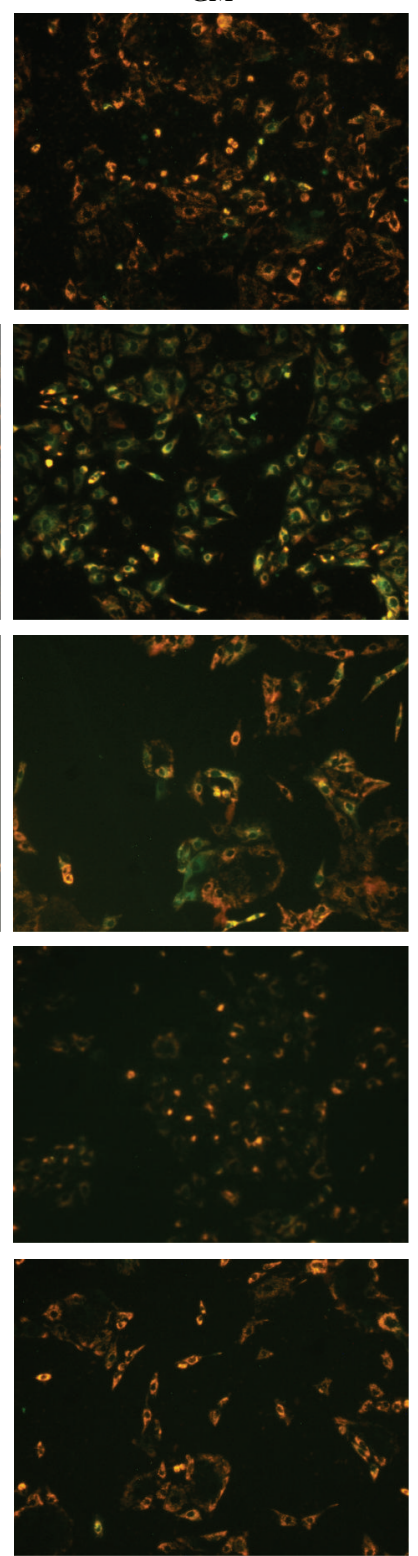

$\mathrm{SFN}+\mathrm{GM}$
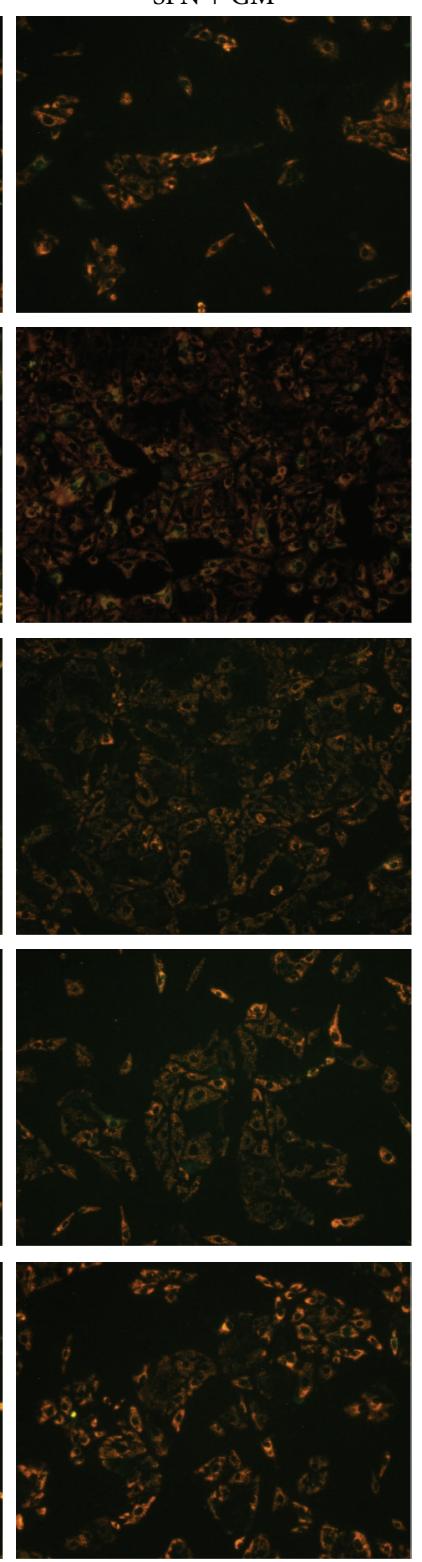

FIGURE 4: SFN treatment preserves the MMP after the exposure to GM in LLC-PK1 cells. MMP was determined by using the JC-1 probe as an indicator of mitochondrial function. Cells were incubated with (SFN and SFN + GM groups) or without (CT and GM groups) $5 \mu \mathrm{M}$ SFN for $24 \mathrm{~h}$, followed by the addition of $8 \mathrm{mM} \mathrm{GM}(\mathrm{GM}), 5 \mu \mathrm{M}$ SFN (SFN), $5 \mu \mathrm{M} \mathrm{SFN}+8 \mathrm{mM}$ GM (SFN + GM), or medium (CT) for 1, 3, 6 , 12 , or $24 \mathrm{~h}$. Cells with depolarized mitochondria are depicted by green fluorescence (monomeric JC-1) and cells with polarized mitochondria are depicted by orange/yellow fluorescence (aggregate JC-1). Mitochondrial depolarization is observed at 3 and $6 \mathrm{~h}$ in cells in the GM group. This fall in MMP is prevented by the SFN treatment. MMP was recovered in the GM groups on $12 \mathrm{~h}$ and $24 \mathrm{~h}$ of GM exposure.

from the SFN + GM group was approximately $40 \%$ of the IOD determined in the GM group $(P<0.05)$ and was similar to the CT group.

\subsection{SFN Treatment Prevents the GM-Induced Protein Nitration} in Rat Renal Cortex. The higher 3-NT immunostaining in the GM group (Figure 10(d)) compared to CT group (Figure 10(b)) was evident. This staining was mainly located at proximal convoluted tubules and in the parietal Bowman epithelium (Figure 10(d)). 3-NT immunostaining in the SFN + GM group (Figure 10(e)) was lower than in the GM group. Automated histomorphometry showed 31- and 13-fold higher 3-NT density expression in GM group than in the CT and SFN + GM groups, respectively $(P<0.05)$.

3.8. SFN Ameliorated GM-Induced Decrease in the Activity of Antioxidant Enzymes CAT and GPx in Renal Cortex. 


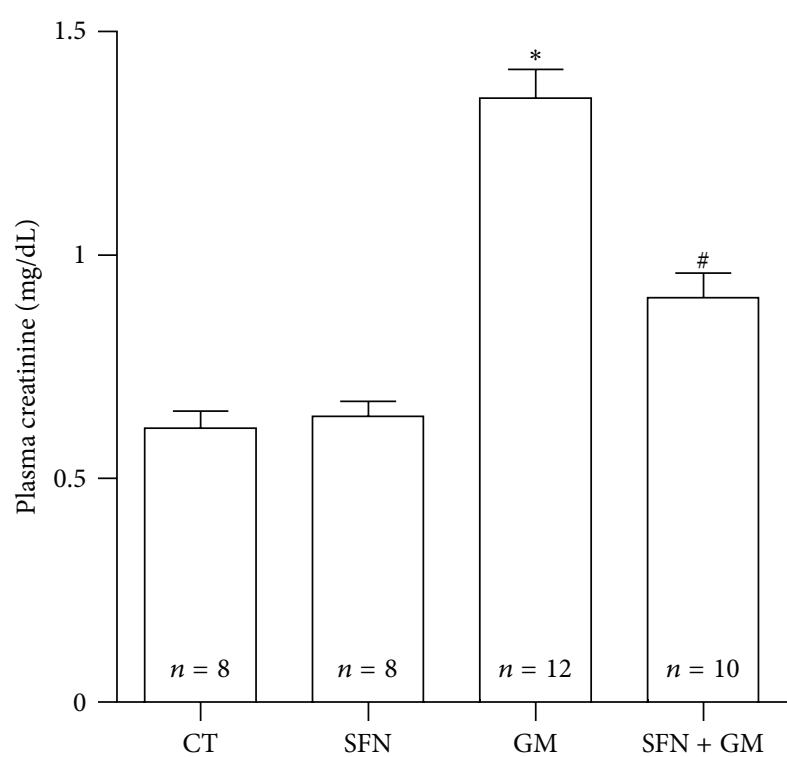

(a)

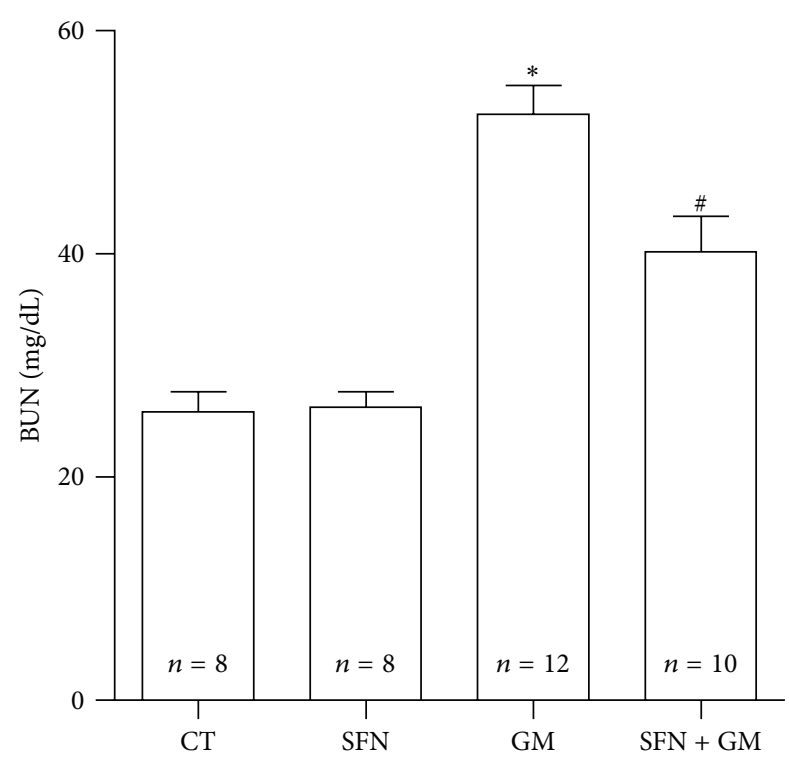

(c)

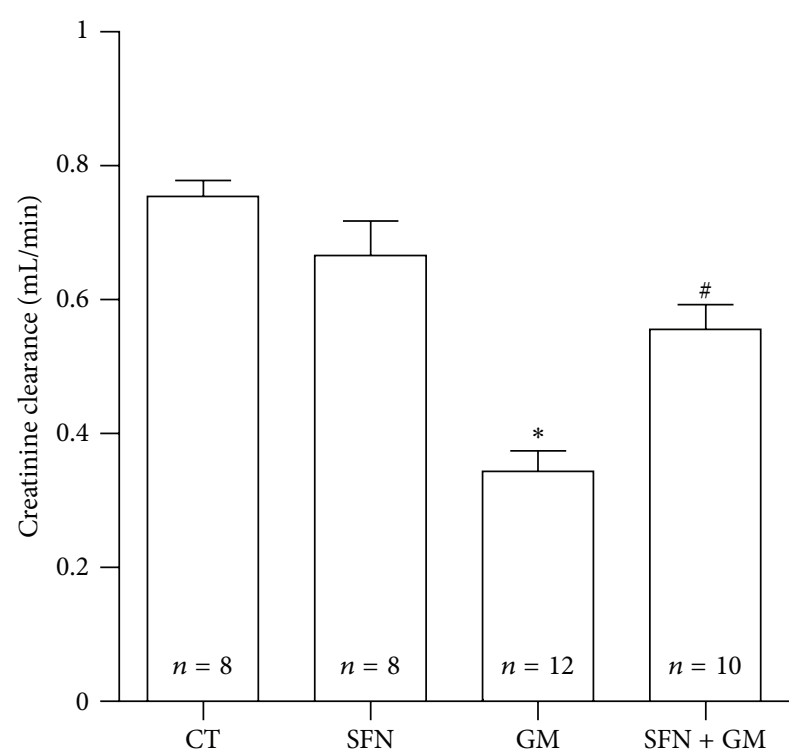

(b)

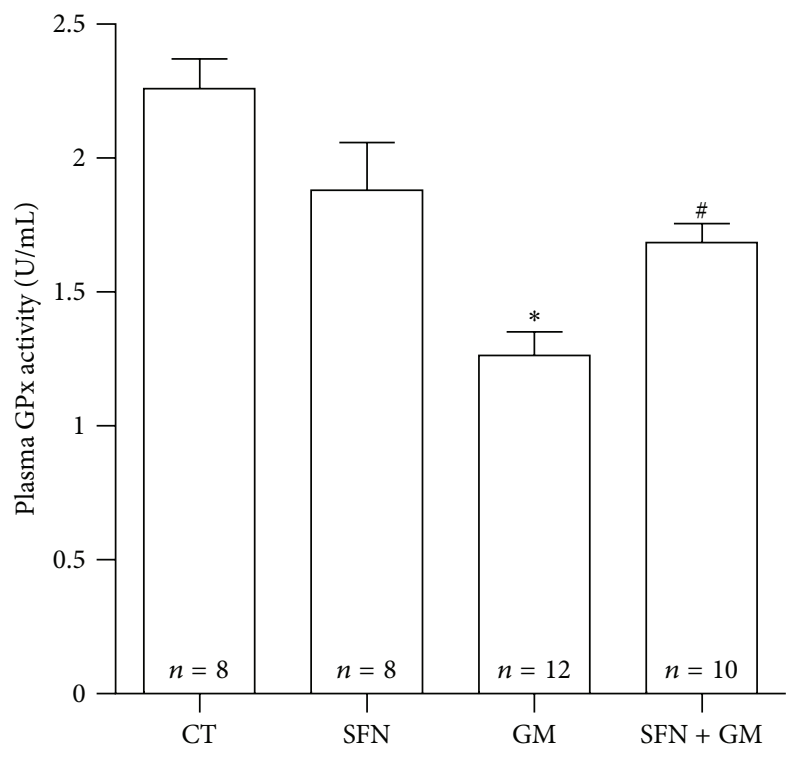

(d)

Figure 5: SFN ameliorates GM-induced renal injury in rats. (a) Plasma creatinine, (b) creatinine clearance, (c) BUN, and (d) plasma GPx activity. Data are mean \pm SEM. ${ }^{*} P<0.001$ versus CT; ${ }^{*} P<0.01$ versus GM.

There was a marked drop in CAT enzymatic activity in the GM group compared to the CT group $(0.26 \pm 0.01$ versus $0.44 \pm 0.01 \mathrm{k} / \mathrm{mg}$ of protein, $P<0.001)$. SFN treatment in the SFN + GM group partially reestablished the activity to approximately $71 \%$ of activity shown by the CT group ( $0.31 \pm$ $0.02 \mathrm{k} / \mathrm{mg}$ of protein, $P<0.05$ versus GM) (Figure 11(a)). A similar behavior was observed when GPx was measured (Figure 11(b)). GPx activity significantly decreased from a mean value of $0.38 \pm 0.02 \mathrm{U} / \mathrm{mg}$ of protein in the CT group to $0.26 \pm 0.01 \mathrm{U} / \mathrm{mg}$ of protein in the GM group $(P<0.001)$. A partial recovery of GPx activity was achieved by the SFN treatment in the SFN + GM group $(0.32 \pm 0.02 \mathrm{U} / \mathrm{mg}$ of protein, $P<0.05$ versus GM).

\section{Discussion}

The in vivo and in vitro data, obtained in the present work, show that SFN is able to attenuate GM-induced nephrotoxicity. SFN was able to prevent GM-induced necrotic and apoptotic cell death. This was evident by phase contrast microscopy, MTT reduction assay, trypan blue exclusion assay, and measurement of fluorescence intensities for annexin V-FITC and PI. 


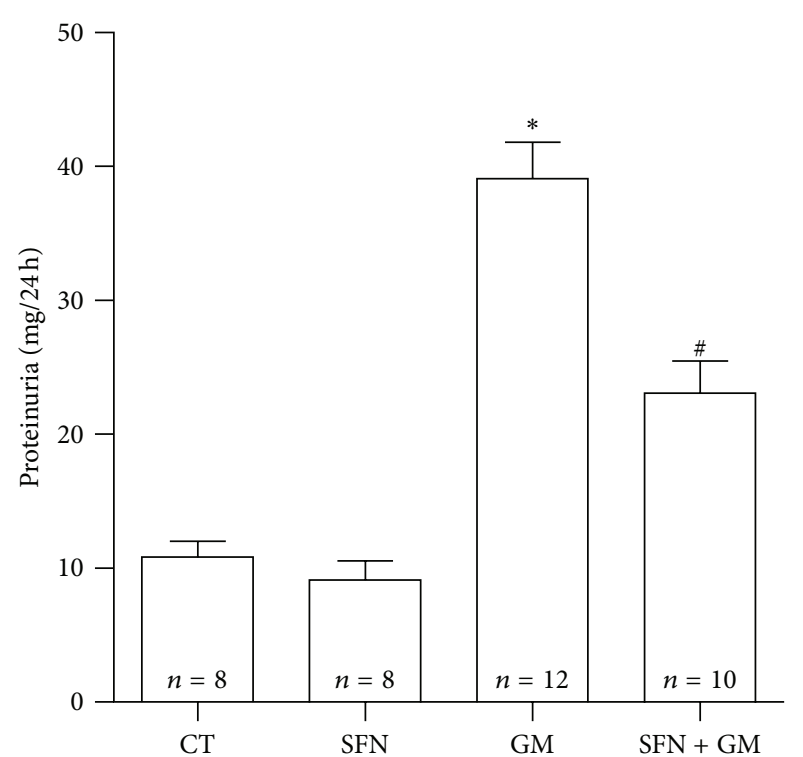

(a)

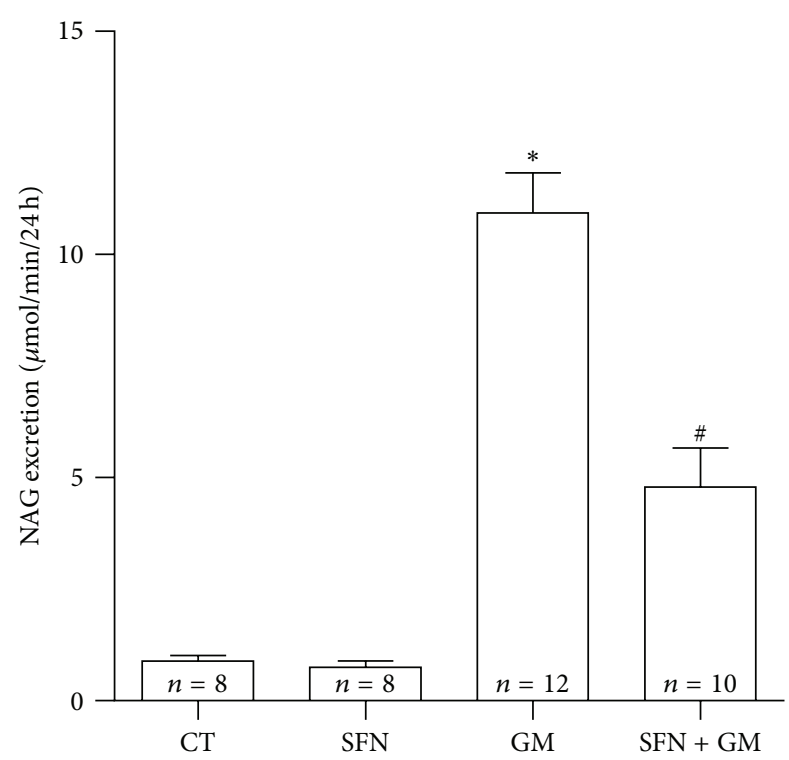

(b)

FIGURE 6: SFN ameliorates GM-induced nephrotoxicity. (a) Proteinuria and (b) urinary NAG excretion in rats. Data are mean \pm SEM. ${ }^{*} P<0.001$ versus $\mathrm{CT}$ and $\mathrm{SFN} ;{ }^{\#} P<0.001$ versus GM.

On the other hand, it was found that SFN alone induces an increase (above control values of $100 \%$ ) in cell viability expressed as MTT reduction but not when it is measured by direct counting of viable cells in the trypan blue exclusion assay. Our group has already observed the same behavior in LLC-PK1 cells incubated with $5 \mu \mathrm{M}$ SFN for only $24 \mathrm{~h}$; in those experiments it was found that SFN prevents cisplatininduced mitochondrial dysfunction and damage in vitro and in vivo [8]. It is known that the MTT assay is a metabolic activity assay that measures mitochondrial function and is used to detect losses in cell survive/viability due to drugs or toxicants [34]. It is possible that the observed increase in MTT reduction is associated with a promotion in mitochondrial functions and respiration rate carried out by SFN rather than an increase in cell population. The drop in MTT reduction at $10 \mu \mathrm{M}$ that forms the bell-like curve showed in Figure 1(e) is the typical hormetic response of many antioxidants.

Given the previous discussion, the protective effect of SFN against GM-induced cell death seen in this work can be linked to the SFN-induced prevention of mitochondrial dysfunction. SFN prevented the GM-induced decrease in MMP at 3 and $6 \mathrm{~h}$. This fact confirms our hypothesis that SFN would prevent GM-induced cell death through mitochondrial protection. It is noteworthy that cells at 12 and $24 \mathrm{~h}$ of GM exposure had less green fluorescence (also less cells) indicating a seeming repolarization of mitochondria. Although there are no reports about alterations in mitochondrial dynamics induced by GM, it has been shown that mitochondria can become fused as a response to stress. Given this mechanism, damaged mitochondria can complement each other and are able to reestablish their MMP [35]. This outcome is not readily explainable but this hypothesis can be the starting point to study the effects of GM on mitochondrial dynamics.

Our in vivo findings corroborate the renoprotective effect of SFN. It was evident that GM-treated rats developed renal damage characterized by proteinuria, elevation in BUN and creatinine blood levels, fall in blood GPx activity and creatinine clearance, and increased urinary excretion of NAG. SFN treatment was able to reduce the GM-induced renal dysfunction, which was evident by the attenuation in the alterations of these markers in the SFN + GM group.

The precursor of SFN is contained in broccoli and this is the reason why several experiments have been done with dietary ingestion of this cruciferous vegetable [1]. The importance of the treatment with SFN instead of extracts or sprouts of broccoli in the GM-induced acute kidney injury should be mentioned. It was established that glucosinolates can be converted to isothiocyanates in humans by bowel microflora, and when this microflora is removed by mechanical cleansing and antibiotics (a mix including neomycin, an AG antibiotic), the conversion of glucosinolates became negligible [36]. Although glucoraphanin in dog and rat plasma after oral dosing of the glucosinolate was detected suggesting that a fraction of it may be absorbed intact to the plasma [37], and it was found that intact glucoraphanin can modulate carcinogen-metabolizing enzyme systems [38], it is unlikely that the broccoli consumption may be successful in this model.

Because of the intense lysosomal activity of renal tubules the raised urinary excretion of lysosomal enzymes is a sensitive marker of GM-induced tubular damage. Our findings, showing the marked decrease of urinary excretion of 


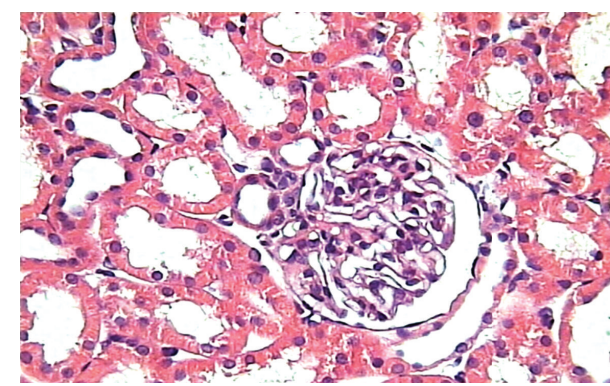

(a)

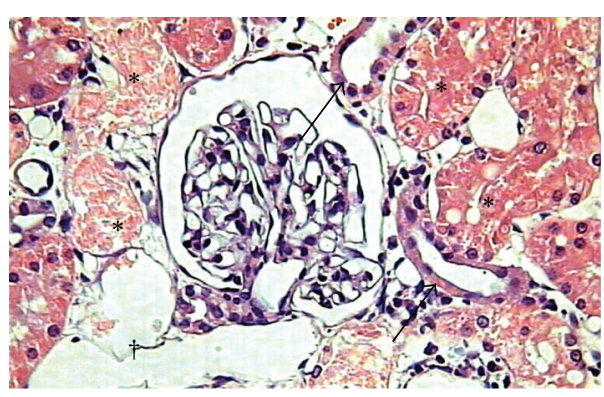

(c)

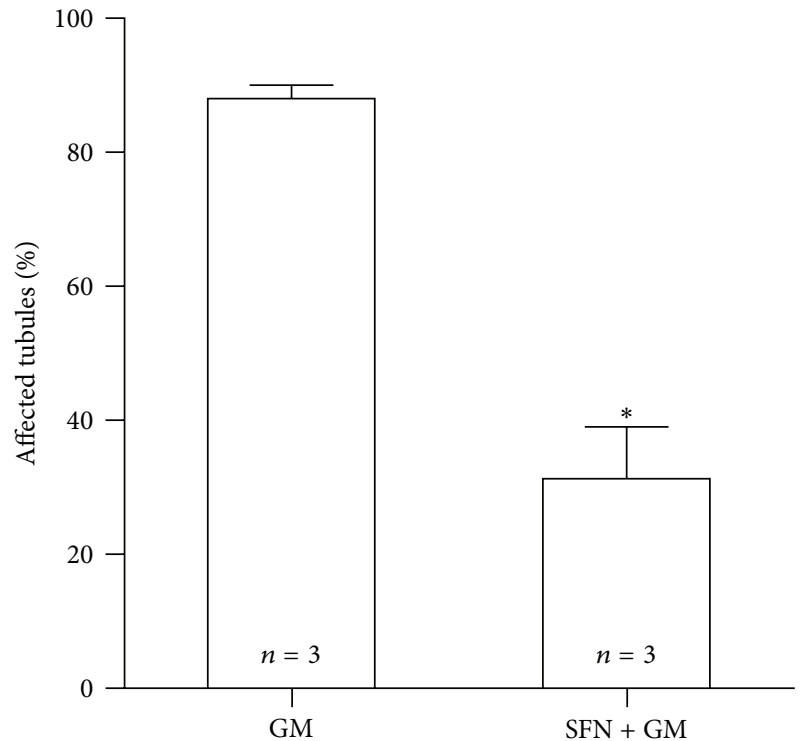

(e)

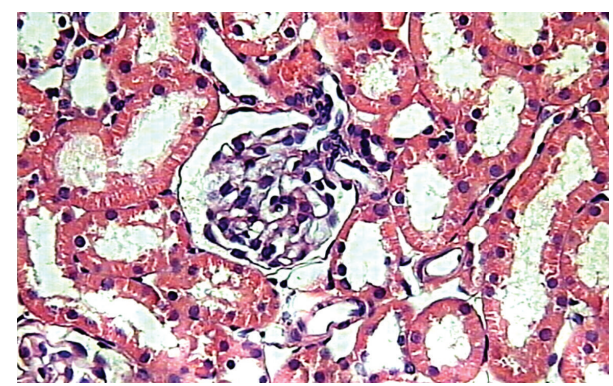

(b)

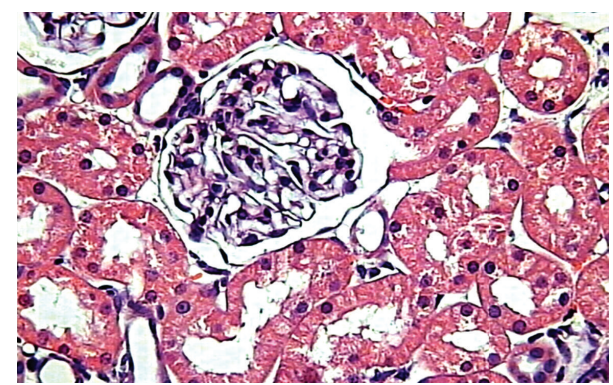

(d)

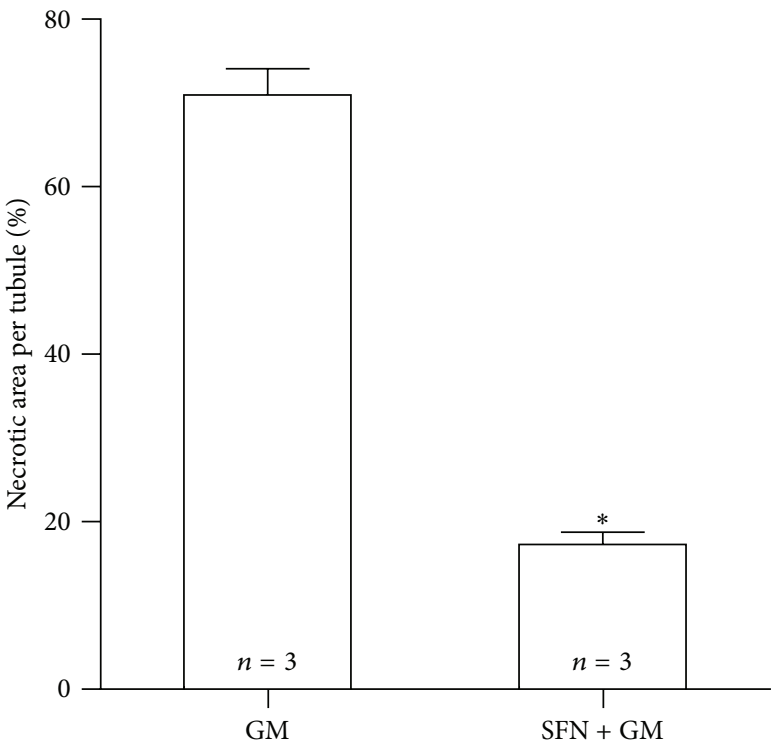

(f)

FIGURE 7: SFN attenuates GM-induced necrosis of proximal tubules. (a-d) Representative renal histopathology of rats studied (H\&E staining). Sections of renal cortex with loss in brush border of proximal tubular epithelium in (c) the GM group can be observed. Asterisks represent either obstruction of tubular lumen or complete loss in tubular structure. Arrows indicate flattening of tubular walls. Cross indicates edema. These alterations are considerably diminished in (d) the SFN + GM group. (a) CT and (b) SFN groups show normal histology (40x). Quantitative morphometry shows an important decrease in (e) damaged tubules and (f) damaged area per tubule in the SFN + GM group compared to the GM group. Data are mean \pm SEM. ${ }^{*} P<0.001$ versus GM.

NAG in rats coadministered with SFN and GM, suggest an important protection of tubular structure. As expected, damaged regions shown by H\&E staining were localized in the renal cortex, affecting mainly proximal tubules in kidneys of GM rats. Kidneys of SFN + GM group showed lesser tissue damage with few epithelial tubular cells affected and almost normal architecture just as the CT control.

Although typical features of necrotic death such as the edematization can be observed, the apoptotic phenotype of death was spread across the renal cortex as was revealed 


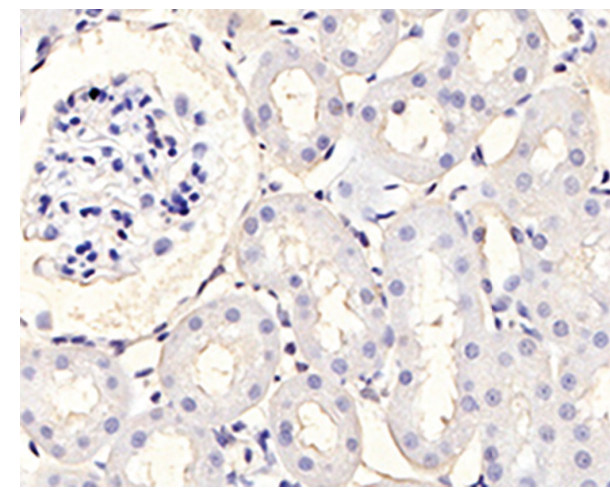

(a)

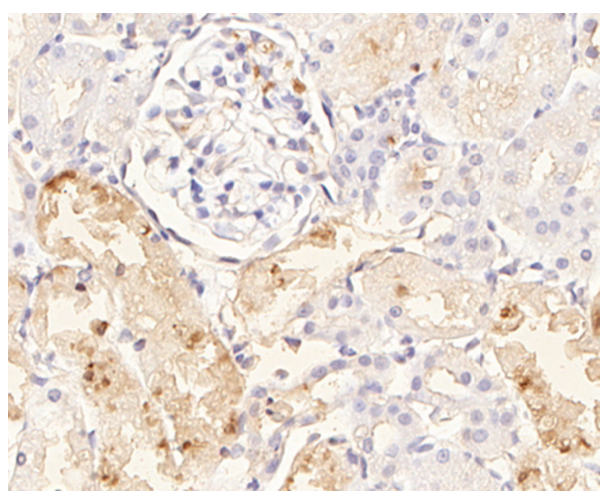

(c)

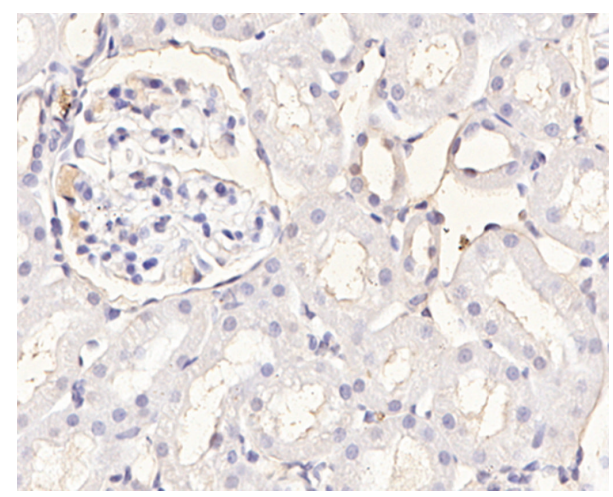

(b)

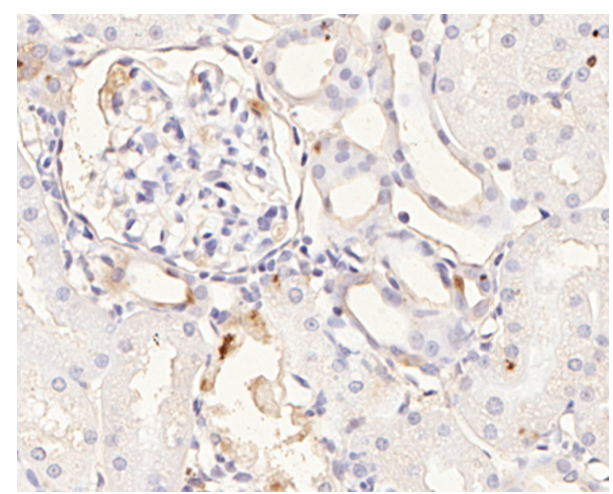

(d)

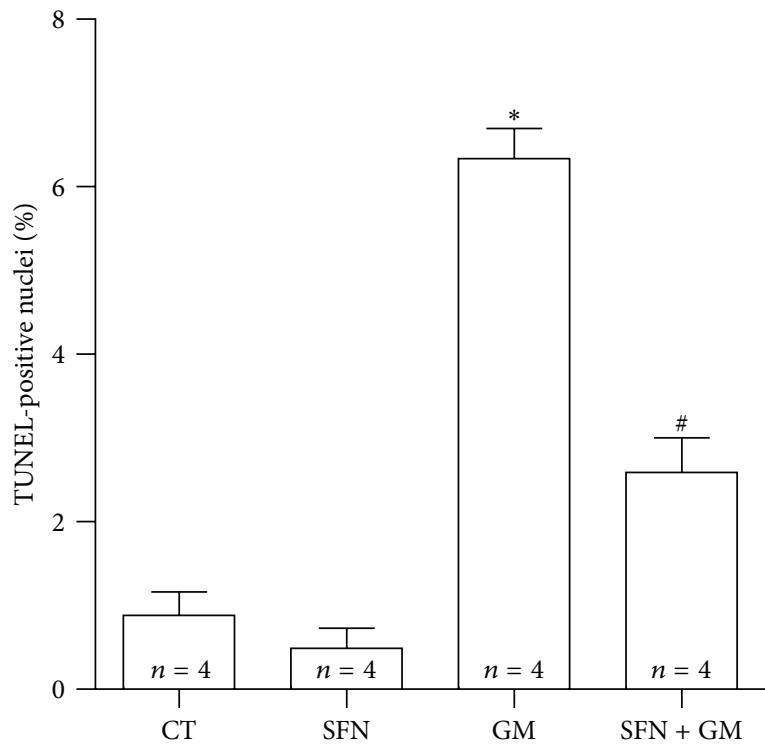

(e)

FIGURE 8: SFN attenuates GM-induced apoptosis.(a-d) Immunohistochemical detection of apoptosis by TUNEL. Sections of renal cortex of (c) rats treated with GM show nuclei intensely stained which indicate tubular cells in apoptosis. (c) There are also several nuclei of glomerular TUNEL-positive cells. Apoptosis was significantly attenuated in (d) the SFN + GM group. Basal staining was observed in renal sections from (a) CT and (b) SFN groups (40x). (e) Quantitative analysis confirms a remarkable protection of SFN against GM-induced apoptotic death in the SFN + GM group. Data are mean \pm SEM. ${ }^{*} P<0.001$ versus CT and SFN; ${ }^{\#} P<0.001$ versus GM. 


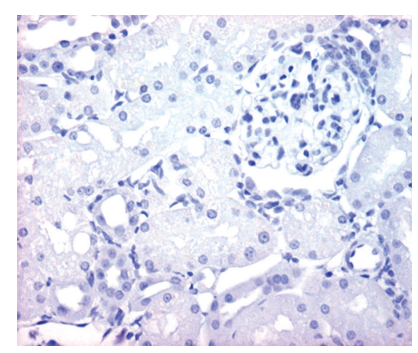

(a)

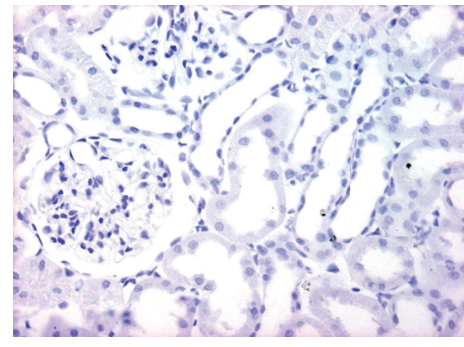

(b)

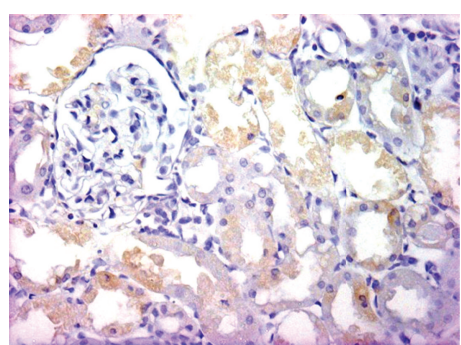

(d)

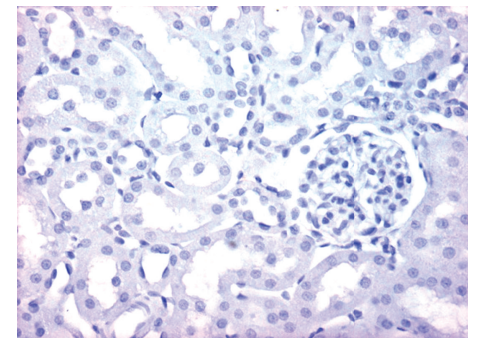

(c)

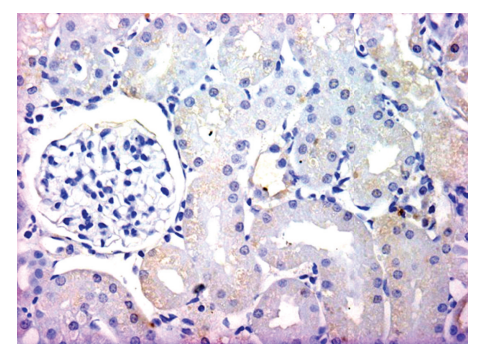

(e)

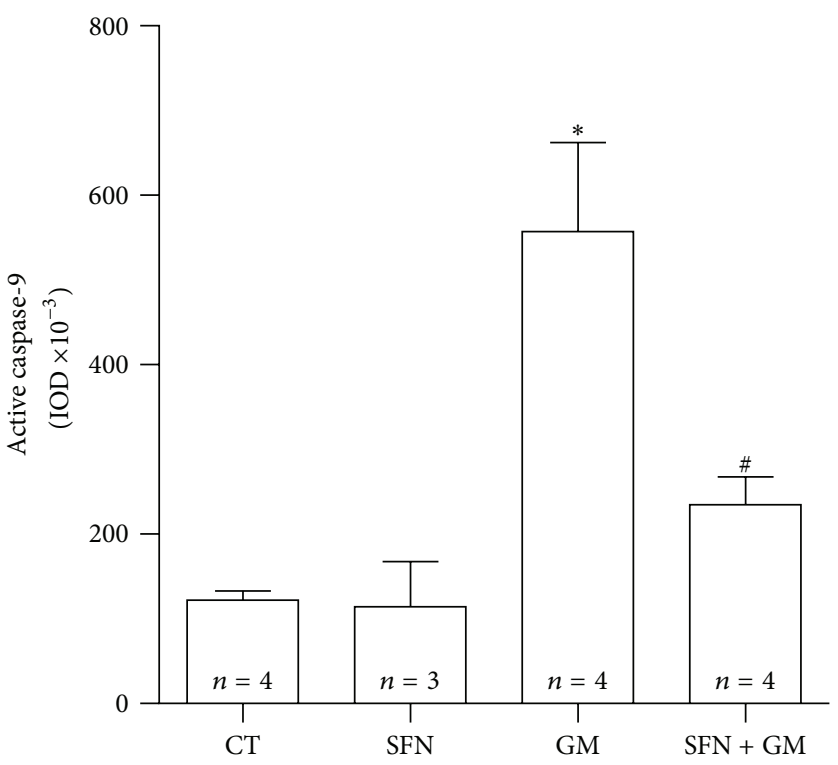

(f)

FIGURE 9: SFN prevents the GM-induced increase in active caspase-9. Representative figures are shown in (b-e) and the isotype control is shown in (a). There is an evident increase in the active caspase-9 immunostaining in (d) GM group compared to (b) CT and (c) SFN groups. The treatment with SFN in the (e) SFN + GM group reduced the caspase-9 activation (40x). (f) Quantification was made by using integrated optical density (IOD) values. Data are mean \pm SEM. ${ }^{*} P<0.01$ versus CT; ${ }^{\#} P<0.05$ versus GM. 


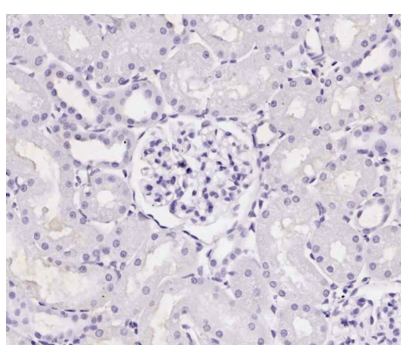

(a)

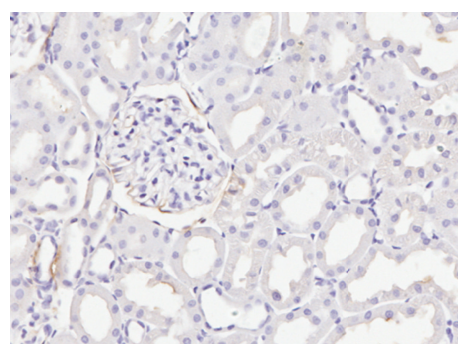

(b)

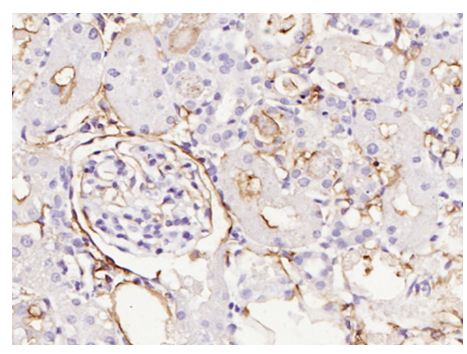

(d)

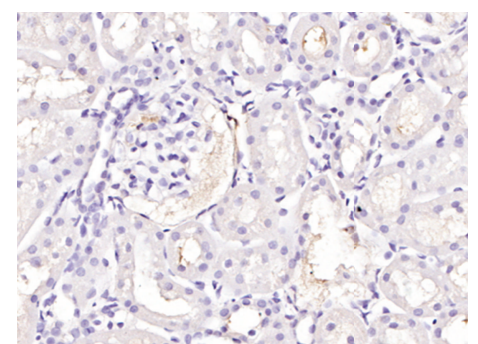

(c)

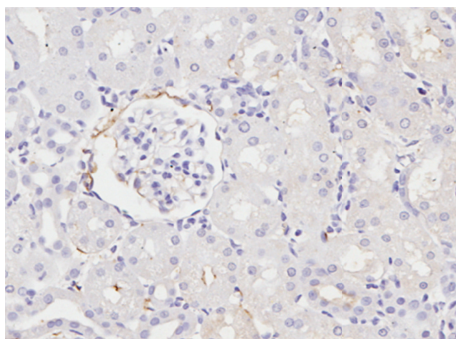

(e)

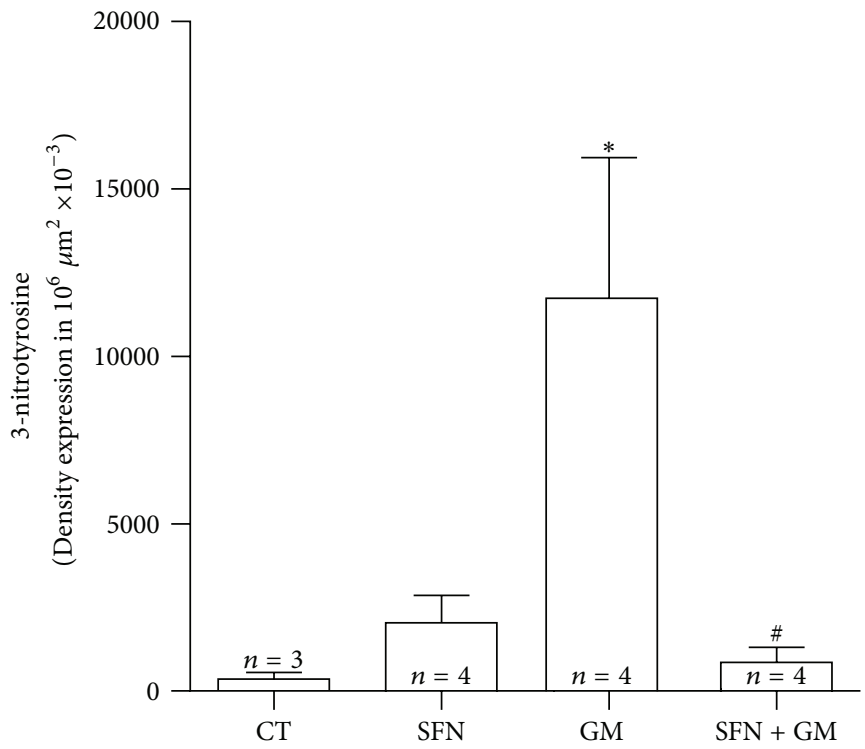

(f)

FIGURE 10: SFN treatment prevents the GM-induced protein nitration in renal cortex. Representative figures are shown in (b-e) and the isotype control is shown in (a). The immunoprevalence of 3-NT in the (d) GM group is higher when it is compared to (e) SFN + GM, (b) CT, and (c) SFN groups. This is mainly expressed in tubular cells and the parietal epithelium of Bowman (40x). (f) Quantification shows that SFN entirely prevents GM-induced protein nitration. Data are mean \pm SEM. ${ }^{*} P<0.05$ versus $C T$; ${ }^{*} P<0.05$ versus GM. 


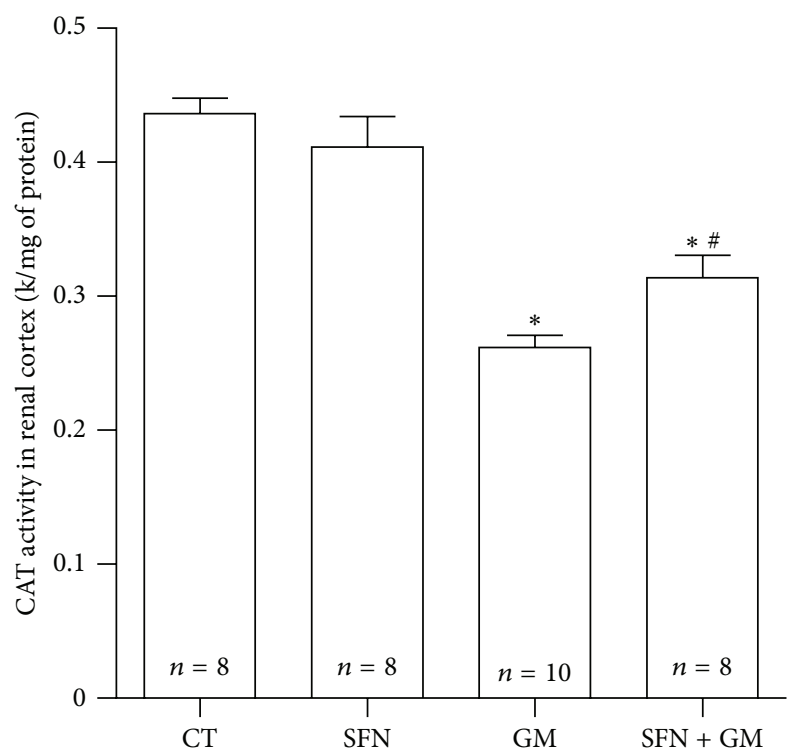

(a)

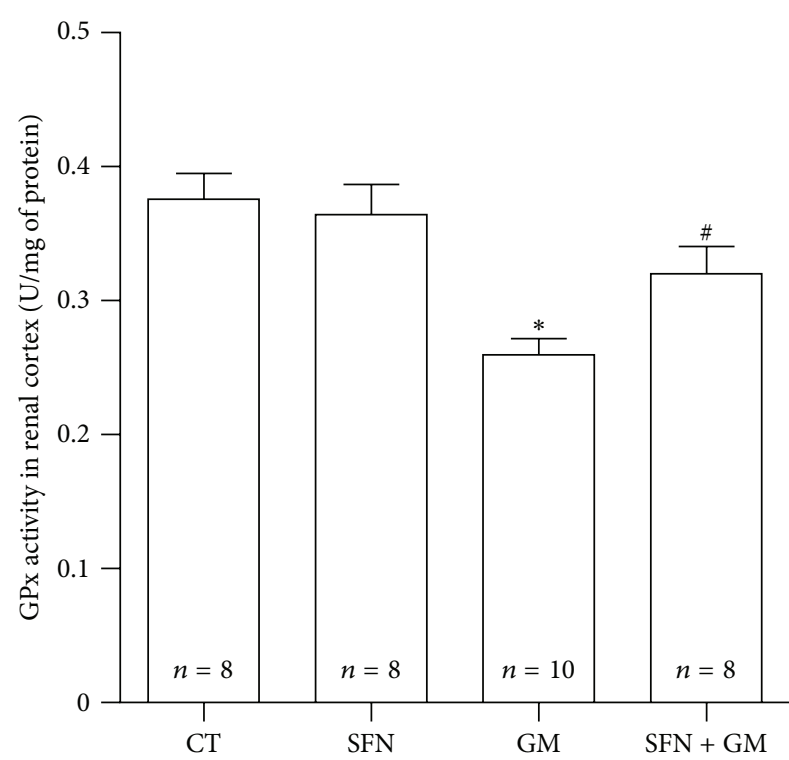

(b)

FIGURE 11: SFN attenuates GM-induced decrease in the activity of antioxidant enzymes (a) CAT and (b) GPx in renal cortex. Data are mean \pm SEM. ${ }^{*} P<0.001$ versus $\mathrm{CT}$; ${ }^{\#} P<0.05$ versus GM.

by the TUNEL assay. The treatment with SFN in rats of the SFN + GM group significantly attenuated the DNA fragmentation due to apoptosis. Clearly, a caspase activated in the mitochondria-dependent apoptosis pathway, caspase9, was detected in tissues of rats from the GM group, while caspase-8, which is activated in extrinsic apoptosis, was not detected. The increment in cleaved caspase-9 was also attenuated by SFN. These last observations strengthen our findings in culture about the mitochondria-protective role of SFN in the GM-induced nephrotoxicity.

Here, it is important to highlight the known dual role of SFN. It has been reported that SFN also induces apoptosis by mitochondrial-dependent pathways in some cancer cell lines, inducing loss of MMP and activating caspase- 9 , at concentrations ranging from moderate $(6 \mu \mathrm{M})$ to high $(25 \mu \mathrm{M})[39,40]$. It seems that SFN can either prevent or induce mitochondrial damage and apoptosis in a doses-dependent way (hormesis) and/or cell-specific way, which deserves to be studied.

Immunohistochemical detection of 3-NT is a useful marker of nitrosative stress, since it has been demonstrated that this compound is formed by the reaction of reactive nitrogen species (RNS) with proteins [41]. In fact, it has been shown that nitric oxide $\left(\mathrm{NO}^{\circ}\right)$ production by nitric oxide synthase-secondary to the transcriptional factor NF- $\kappa \mathrm{B}$ induction-is implicated in the GM-induced renal toxicity [42]. It is worth noting that $\mathrm{NO}^{\circ}$ inhibits the components of the electron transfer chain at different sensitivities. The segmental inhibition of complex I-III by $\mathrm{NO}^{\circ}$ is also followed by very high burst of superoxide production rate. As a consequence, the level of reduction of the mitochondrial components favors additional reactions of $\mathrm{NO}^{-}$with ubiquinol and the formation of peroxynitrite $\left(\mathrm{ONOO}^{-}\right)$[43] .
Interestingly, SFN was also able to entirely prevent the GMinduced elevation in 3-NT suggesting that SFN, through its indirect action, could be preventing the generation of $\mathrm{NO}^{\circ}$, the mitochondrial dysfunction mediated by $\mathrm{NO}^{\circ}$, and the formation of $\mathrm{ONOO}^{-}$involved in protein nitration.

Finally, it was found that SFN attenuated the loss of activity of the antioxidant enzymes catalase and GPx in renal cortex. It has been demonstrated that catalase is affected by ROS due to its high susceptibility to carbonylation [44], and GPx can be inactivated by $\mathrm{NO}^{\circ}$, carbonylic compounds, or diminished GSH levels $[45,46]$. Given those facts, probably the renoprotective effect of SFN is also mediated by controlling the generation of ROS/RNS and prevention of oxidative/nitrosative stress.

In conclusion, our results show that SFN treatment protects kidneys and renal tubular cells against GM-induced toxicity and suggest that this protective effect would be associated with prevention of nitrosative stress and/or, mainly, preservation in mitochondrial functions.

\section{Conflict of Interests}

The authors do not have any conflict of interests regarding the content of the paper.

\section{Acknowledgments}

This work was supported by PAPIIT (Grants IN201910 and IN210713) and CONACYT (Grants 167949 and 129838). 


\section{References}

[1] C. E. Guerrero-Beltrán, M. Calderón-Oliver, J. Pedraza-Chaverri, and Y. I. Chirino, "Protective effect of sulforaphane against oxidative stress: recent advances," Experimental and Toxicologic Pathology, vol. 64, no. 5, pp. 503-508, 2012.

[2] A. T. Dinkova-Kostova and R. V. Kostov, "Glucosinolates and isothiocyanates in health and disease," Trends in Molecular Medicine, vol. 18, no. 6, pp. 337-347, 2012.

[3] H. R. Vasanthi, S. Mukherjee, and D. K. Das, "Potential health benefits of broccoli-a chemico-biological overview," MiniReviews in Medicinal Chemistry, vol. 9, no. 6, pp. 749-759, 2009.

[4] A. T. Dinkova-Kostova and P. Talalay, "Direct and indirect antioxidant properties of inducers of cytoprotective proteins," Molecular Nutrition and Food Research, vol. 52, supplement 1, pp. S128-S138, 2008.

[5] L. Gaona-Gaona, E. Molina-Jijón, E. Tapia et al., "Protective effect of sulforaphane pretreatment against cisplatin-induced liver and mitochondrial oxidant damage in rats," Toxicology, vol. 286, no. 1-3, pp. 20-27, 2011.

[6] T. Greco and G. Fiskum, "Brain mitochondria from rats treated with sulforaphane are resistant to redox-regulated permeability transition," Journal of Bioenergetics and Biomembranes, vol. 42, no. 6 , pp. 491-497, 2010.

[7] T. Greco, J. Shafer, and G. Fiskum, "Sulforaphane inhibits mitochondrial permeability transition and oxidative stress," Free Radical Biology \& Medicine, vol. 51, no. 12, pp. 2164-2171, 2011.

[8] C. E. Guerrero-Beltrán, M. Calderón-Oliver, E. MartínezAbundis et al., "Protective effect of sulforaphane against cisplatin-induced mitochondrial alterations and impairment in the activity of $\mathrm{NAD}(\mathrm{P}) \mathrm{H}$ : quinone oxidoreductase 1 and $\gamma$ glutamyl cysteine ligase: studies in mitochondria isolated from rat kidney and in LLC-PK1 cells," Toxicology Letters, vol. 199, no. 1, pp. 80-92, 2010.

[9] D. K. D. Priya, R. Gayathri, G. R. Gunassekaran, and D. Sakthisekaran, "Protective role of sulforaphane against oxidative stress mediated mitochondrial dysfunction induced by benzo(a)pyrene in female Swiss albino mice," Pulmonary Pharmacology \& Therapeutics, vol. 24, no. 1, pp. 110-117, 2011.

[10] C. S. Piao, S. Gao, G.-H. Lee et al., "Sulforaphane protects ischemic injury of hearts through antioxidant pathway and mitochondrial K(ATP) channels," Pharmacological Research, vol. 61, no. 4, pp. 342-348, 2010.

[11] N. Juge, R. F. Mithen, and M. Traka, "Molecular basis for chemoprevention by sulforaphane: a comprehensive review," Cellular and Molecular Life Sciences, vol. 64, no. 9, pp. 1105-1127, 2007.

[12] X. Sun, L. Mi, J. Liu, L. Song, F.-L. Chung, and N. Gan, "Sulforaphane prevents microcystin-LR-induced oxidative damage and apoptosis in BALB/c mice," Toxicology and Applied Pharmacology, vol. 255, no. 1, pp. 9-17, 2011.

[13] P. Balakumar, A. Rohilla, and A. Thangathirupathi, "Gentamicin-induced nephrotoxicity: do we have a promising therapeutic approach to blunt it?" Pharmacological Research, vol. 62, no. 3, pp. 179-186, 2010.

[14] J. M. Lopez-Novoa, Y. Quiros, L. Vicente, A. I. Morales, and F. J. Lopez-Hernandez, "New insights into the mechanism of aminoglycoside nephrotoxicity: an integrative point of view," Kidney International, vol. 79, no. 1, pp. 33-45, 2011.
[15] N. M. Selby, S. Shaw, N. Woodier, R. J. Fluck, and N. V. Kolhe, "Gentamicin-associated acute kidney injury," QJM, vol. 102, no. 12, pp. 873-880, 2009.

[16] W. M. Sweileh, "A prospective comparative study of gentamicinand amikacin-induced nephrotoxicity in patients with normal baseline renal function," Fundamental \& Clinical Pharmacology, vol. 23, no. 4, pp. 515-520, 2009.

[17] M. Zappitelli, B. S. Moffett, A. Hyder, and S. L. Goldstein, "Acute kidney injury in non-critically ill children treated with aminoglycoside antibiotics in a tertiary healthcare centre: a retrospective cohort study," Nephrology Dialysis Transplantation, vol. 26, no. 1, pp. 144-150, 2011.

[18] H. Servais, P. Van Der Smissen, G. Thirion et al., "Gentamicininduced apoptosis in LLC-PK1 cells: involvement of lysosomes and mitochondria," Toxicology and Applied Pharmacology, vol. 206, no. 3, pp. 321-333, 2005.

[19] A. I. Morales, D. Detaille, M. Prieto et al., "Metformin prevents experimental gentamicin-induced nephropathy by a mitochondria-dependent pathway," Kidney International, vol. 77, no. 10, pp. 861-869, 2010.

[20] D. B. Zorov, "Amelioration of aminoglycoside nephrotoxicity requires protection of renal mitochondria," Kidney International, vol. 77, no. 10, pp. 841-843, 2010.

[21] E. A. Pessoa, M. B. Convento, R. G. Silva, A. S. Oliveira, F. T. Borges, and N. Schor, "Gentamicin-induced preconditioning of proximal tubular LLC-PK1 cells stimulates nitric oxide production but not the synthesis of heat shock protein," Brazilian Journal of Medical and Biological Research, vol. 42, no. 7, pp. 614620, 2009.

[22] H. Servais, Y. Jossin, F. Van Bambeke, P. M. Tulkens, and M.P. Mingeot-Leclercq, "Gentamicin causes apoptosis at low concentrations in renal LLC-PK1 cells subjected to electroporation," Antimicrobial Agents and Chemotherapy, vol. 50, no. 4, pp. 12131221, 2006.

[23] C. A. Tagliati, D. Romero, E. C. R. Dutra, A. Hernández-García, E. Martínez-López, and A. J. García-Fernández, "A comparison of BGM and LLC-PK1 cells for the evaluation of nephrotoxicity," Drug and Chemical Toxicology, vol. 35, no. 3, pp. 258-263, 2012.

[24] M. A. Velasco-Velázquez, P. D. Maldonado, D. Barrera, V. Torres, A. Zentella-Dehesa, and J. Pedraza-Chaverrí, "Aged garlic extract induces proliferation and ameliorates gentamicininduced toxicity in LLC-PK1 cells," Phytotherapy Research, vol. 20, no. 1, pp. 76-78, 2006.

[25] S. Quesney, J. Marvel, A. Marc, C. Gerdil, and B. Meignier, "Characterization of Vero cell growth and death in bioreactor with serum-containing and serum-free media," Cytotechnology, vol. 35, no. 2, pp. 115-125, 2001.

[26] N. Adhikari, N. Sinha, and D. K. Saxena, "Effect of lead on Sertoli-germ cell coculture of rat," Toxicology Letters, vol. 116, no. 1-2, pp. 45-49, 2000.

[27] S. T. Smiley, M. Reers, C. Mottola-Hartshorn et al., "Intracellular heterogeneity in mitochondrial membrane potentials revealed by a J-aggregate-forming lipophilic cation JC-1," Proceedings of the National Academy of Sciences of the United States of America, vol. 88, no. 9, pp. 3671-3675, 1991.

[28] P. D. Maldonado, D. Barrera, I. Rivero et al., "Antioxidant Sallylcysteine prevents gentamicin-induced oxidative stress and renal damage," Free Radical Biology and Medicine, vol. 35, no. 3, pp. 317-324, 2003.

[29] J. Pedraza-Chaverrí, D. Barrera, P. D. Maldonado et al., "Sallylmercaptocysteine scavenges hydroxyl radical and singlet 
oxygen in vitro and attenuates gentamicin-induced oxidative and nitrosative stress and renal damage in vivo," BMC Clinical Pharmacology, vol. 4, article 5, 2004.

[30] J. Pedraza-Chaverrí, P. D. Maldonado, O. N. Medina-Campos et al., "Garlic ameliorates gentamicin nephrotoxicity: relation to antioxidant enzymes," Free Radical Biology and Medicine, vol. 29, no. 7, pp. 602-611, 2000.

[31] P. D. Maldonado, D. Barrera, O. N. Medina-Campos, R. Hernández-Pando, M. E. Ibarra-Rubio, and J. Pedraza-Chaverrí, "Aged garlic extract attenuates gentamicin induced renal damage and oxidative stress in rats," Life Sciences, vol. 73, no. 20, pp. 2543-2556, 2003.

[32] K. Jung, F. Priem, W. Henke, S. Klotzek, and S. Becker, "Evaluation of methods for determining $\mathrm{N}$-acetyl-beta-Dglucosaminidase in urine of rats without purification of urine samples," Journal of Experimental Animal Science, vol. 34, no. 4, pp. 147-152, 1991.

[33] C. E. Guerrero-Beltrán, M. Calderón-Oliver, E. Tapia et al., "Sulforaphane protects against cisplatin-induced nephrotoxicity," Toxicology Letters, vol. 192, no. 3, pp. 278-285, 2010.

[34] V. N. Sumantran, "Cellular chemosensitivity assays: an overview," Cancer Cell Culture, vol. 731, pp. 219-236, 2011.

[35] B. Westermann, "Mitochondrial fusion and fission in cell life and death," Nature Reviews Molecular Cell Biology, vol. 11, no. 12, pp. 872-884, 2010.

[36] T. A. Shapiro, J. W. Fahey, K. L. Wade, K. K. Stephenson, and P. Talalay, "Human metabolism and excretion of cancer chemoprotective glucosinolates and isothiocyanates of cruciferous vegetables," Cancer Epidemiology, Biomarkers \& Prevention, vol. 7, no. 12, pp. 1091-1100, 1998.

[37] M. J. Cwik, H. Wu, M. Muzzio, D. L. McCormick, and I. Kapetanovic, "Direct quantitation of glucoraphanin in dog and rat plasma by LC-MS/MS," Journal of Pharmaceutical and Biomedical Analysis, vol. 52, no. 4, pp. 544-549, 2010.

[38] A. F. Abdull Razis, M. Bagatta, G. R. De Nicola, R. Iori, and C. Ioannides, "Up-regulation of cytochrome P450 and phase II enzyme systems in rat precision-cut rat lung slices by the intact glucosinolates, glucoraphanin and glucoerucin," Lung Cancer, vol. 71, no. 3, pp. 298-305, 2011.

[39] M.-J. Chen, W.-Y. Tang, C.-W. Hsu et al., "Apoptosis induction in primary human colorectal cancer cell lines and retarded tumor growth in SCID mice by sulforaphane," Evidence-Based Complementary and Alternative Medicine, vol. 2012, Article ID 415231, 13 pages, 2012.

[40] A. Pledgie-Tracy, M. D. Sobolewski, and N. E. Davidson, "Sulforaphane induces cell type-specific apoptosis in human breast cancer cell lines," Molecular Cancer Therapeutics, vol. 6, no. 3, pp. 1013-1021, 2007.

[41] C. Szabó, "Multiple pathways of peroxynitrite cytotoxicity," Toxicology Letters, vol. 140-141, pp. 105-112, 2003.

[42] R. Manikandan, M. Beulaja, R. Thiagarajan, A. Priyadarsini, R. Saravanan, and M. Arumugam, "Ameliorative effects of curcumin against renal injuries mediated by inducible nitric oxide synthase and nuclear factor kappa B during gentamicininduced toxicity in Wistar rats," European Journal of Pharmacology, vol. 670, no. 2-3, pp. 578-585, 2011.

[43] V. G. Antico Arciuch, M. E. Elguero, J. J. Poderoso, and M. C. Carreras, "Mitochondrial regulation of cell cycle and proliferation," Antioxidants \& Redox Signaling, vol. 16, no. 10, pp. 1150-1180, 2012.
[44] L. B. Pena, C. E. Azpilicueta, and S. M. Gallego, "Sunflower cotyledons cope with copper stress by inducing catalase subunits less sensitive to oxidation," Journal of Trace Elements in Medicine and Biology, vol. 25, no. 3, pp. 125-129, 2011.

[45] Y. Miyamoto, Y. H. Koh, Y. S. Park et al., "Oxidative stress caused by inactivation of glutathione peroxidase and adaptive responses," Biological Chemistry, vol. 384, no. 4, pp. 567-574, 2003.

[46] M. Kinter and R. J. Roberts, "Glutathione consumption and glutathione peroxidase inactivation in fibroblast cell lines by 4 hydroxy-2-nonenal," Free Radical Biology and Medicine, vol. 21, no. 4, pp. 457-462, 1996. 


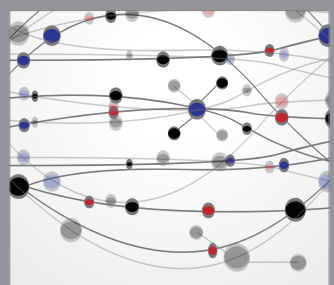

The Scientific World Journal
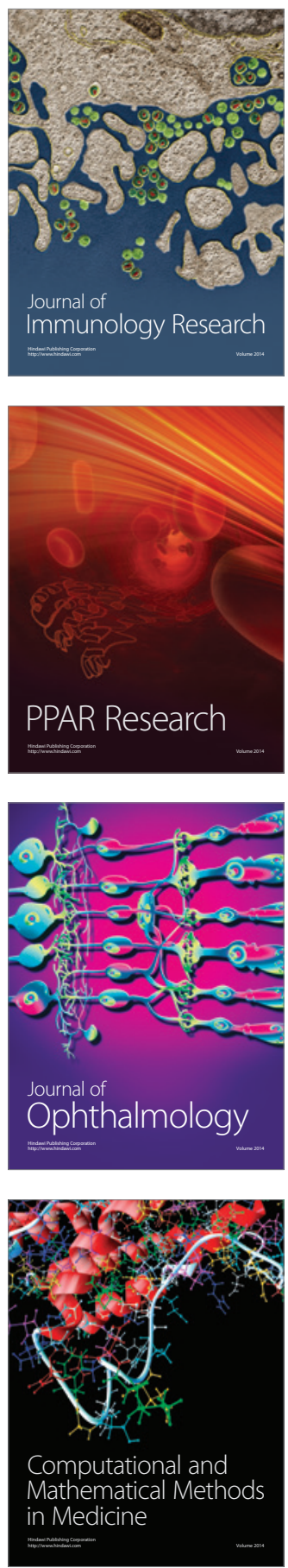

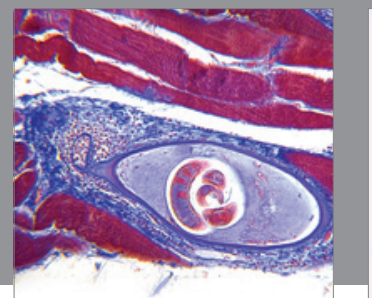

Gastroenterology

Research and Practice
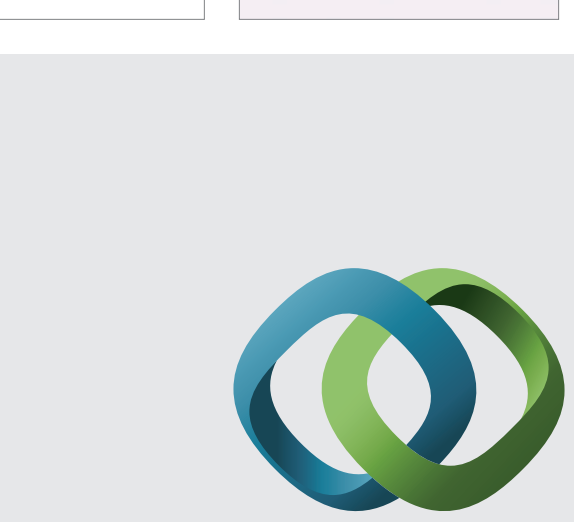

\section{Hindawi}

Submit your manuscripts at

http://www.hindawi.com
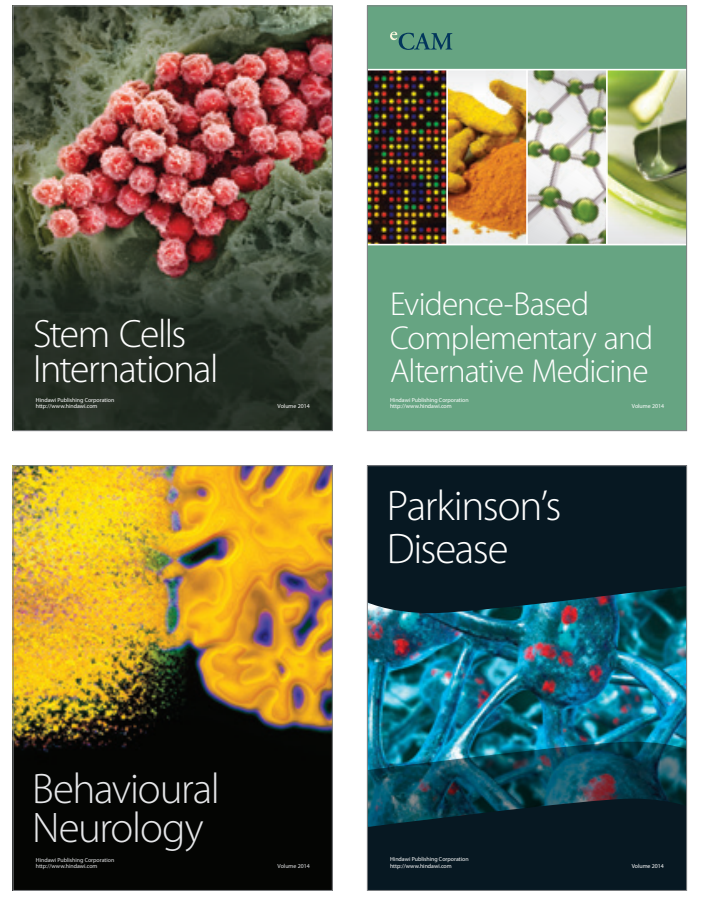
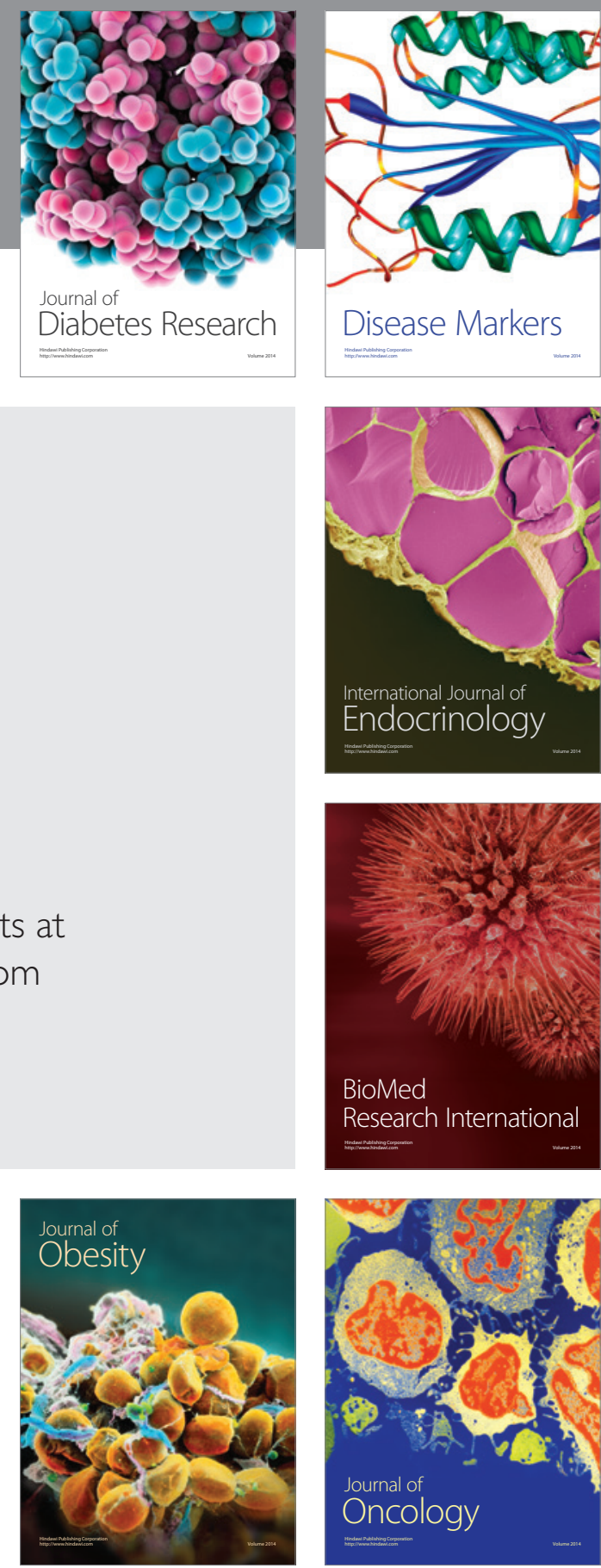

Disease Markers
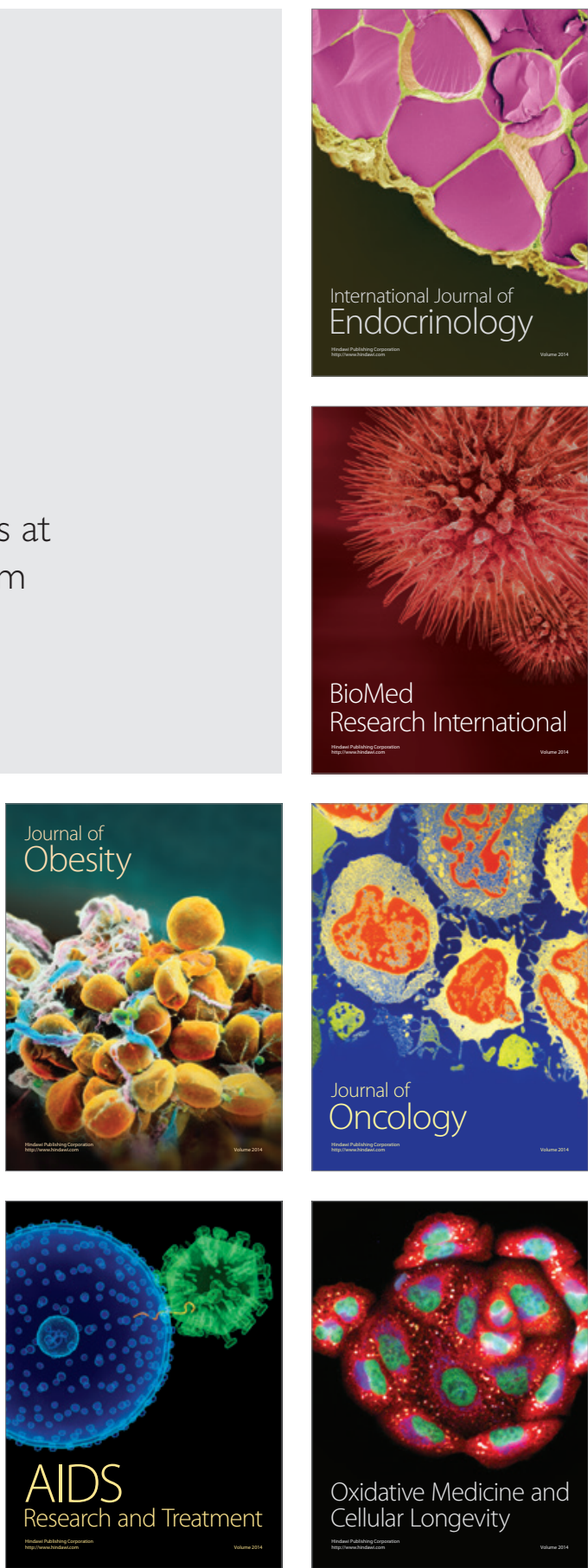